\title{
A study of teacher perceptions of the relationship between leadership styles of principals in high and low performing West Virginia elementary schools
}

\author{
Gus E. Penix \\ West Virginia University
}

Follow this and additional works at: https://researchrepository.wvu.edu/etd

\footnotetext{
Recommended Citation

Penix, Gus E., "A study of teacher perceptions of the relationship between leadership styles of principals in high and low performing West Virginia elementary schools" (2009). Graduate Theses, Dissertations, and Problem Reports. 4511.

https://researchrepository.wvu.edu/etd/4511

This Dissertation is protected by copyright and/or related rights. It has been brought to you by the The Research Repository @ WVU with permission from the rights-holder(s). You are free to use this Dissertation in any way that is permitted by the copyright and related rights legislation that applies to your use. For other uses you must obtain permission from the rights-holder(s) directly, unless additional rights are indicated by a Creative Commons license in the record and/ or on the work itself. This Dissertation has been accepted for inclusion in WVU Graduate Theses, Dissertations, and Problem Reports collection by an authorized administrator of The Research Repository @ WVU. For more information, please contact researchrepository@mail.wvu.edu.
} 


\title{
A STUDY OF TEACHER PERCEPTIONS OF THE RELATIONSHIP BETWEEN LEADERSHIP STYLES OF PRINCIPALS IN HIGH AND LOW PERFORMING WEST VIRGINIA ELEMENTARY SCHOOLS
}

\author{
Gus E. Penix \\ Dissertation submitted to the \\ College of Human Resources and Education \\ at West Virginia University \\ in partial fulfillment of the requirements \\ for the degree of
}

Doctor of Education in Educational Leadership Studies

\author{
Richard Hartnett, Ed.D., Chair \\ Paul Chapman, Ph.D. \\ Martha Dean, Ed.D. \\ Helen Hazi, Ph.D. \\ Neal Shambaugh, Ph.D. \\ Department of Advanced Educational Studies \\ Morgantown, West Virginia \\ 2009
}

Keywords: Principals; Leadership Styles; Frame Utilization 


\begin{abstract}
A Study of Teacher Perceptions of the Relationship Between Leadership Styles of Principals in High and Low Performing West Virginia Elementary Schools
\end{abstract}

Gus E. Penix

This study sought to identify differences in the leadership styles of principals in high and low performing West Virginia elementary schools based on teacher perceptions from the Bolman and Deal Leadership Orientation (Other) instrument. The reading/language arts and mathematics index was used to classify high and low performing schools. Twenty-seven principals (13 in high performing schools; 14 in low performing schools) and 196 teachers (88 in high performing schools; 108 in low performing schools) responded to the surveys. Descriptive statistics, ANOVA, and t-tests were used to analyze data.

The major findings regarding principals' frame utilization were: (1) principals in high performing schools are significantly more likely to use all four frames than principals in low performing schools; (2) female principals are significantly more likely to use the human resource frame than male principals; (3) rural principals are significantly more likely to use the political frame than urban principals; and (4) principals in small size schools are significantly more likely to use the human resource frame than principals in medium size schools. The multi-frame principals tended to be female with 0-5 years administrative experience in small, rural schools.

The major recommendation was that low performing principals with no, single, and paired frame leadership receive professional development to become multi-frame leaders, and thereby enhance the educational performance of their schools. 


\section{TABLE OF CONTENTS}

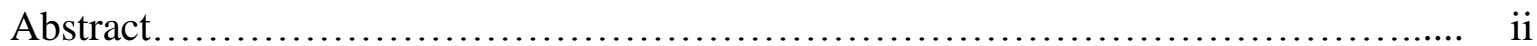

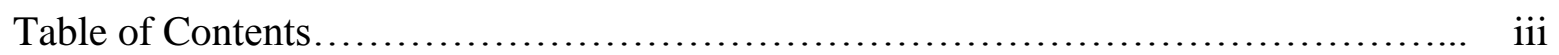

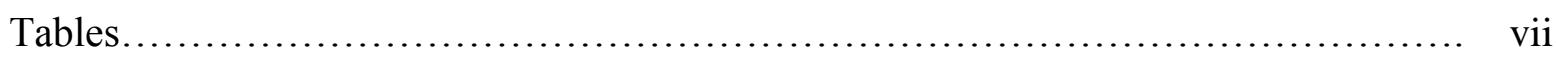

Chapter One - Introduction to the Study .................................. 1

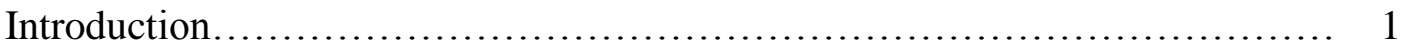

Principal Leadership........................................... 1

Principal As Instructional Leader.................................. 3

Statement of the Problem............................................... 5

Research Questions/Hypotheses.................................... 6

Significance of the Study.......................................... 8

Limitations of the Study.......................................... 8

Assumptions.................................................... 9

Definition of Terms.................................................... 9

Organization of the Study............................................ 12

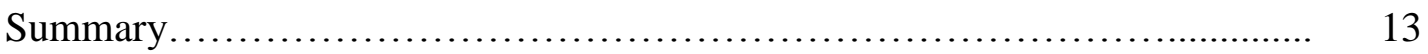

Chapter Two - Literature Review...................................... 14

Study of Leadership.............................................. 14

Traits Model.................................................... 15

Behavior Model.............................................. 16

Situational/Contingency Model.................................... 17

Transformational Model......................................... 19

The Conceptual Framework for this Study $\ldots \ldots \ldots \ldots \ldots \ldots \ldots \ldots \ldots \ldots \ldots \ldots . . \ldots \ldots \ldots$

School Culture................................................ 21 
Teacher Perceptions of Principal Leadership Styles.................. $\quad 25$

West Virginia Elementary Schools................................ 25

West Virginia High and Low Performing Elementary Schools............... $\quad 26$

Bolman and Deal's Four Frame Leadership Orientation Model.......... 27

Bolman and Deal - Multi-Frame Leadership........................ 33

Bolman and Deal's Leadership Model in Action...................... 34

Studies Regarding Bolman and Deal's Four Frame Model.............. 37

Studies of the Four Frame Model Relative to This Study................ 40

Principals' Leadership and Student Achievement.......................... 47

Reports and Legislation Impacting Principal Leadership............... 47

The Effective Schools Movement - Instructional Leadership............ 48

Studies of Principals' Leadership and Student Achievement............ 51

$21^{\text {st }}$ Century Initiatives for Improving Principals’ Leadership.................. 54

School Leadership for the $21^{\text {st }}$ Century Initiative...................... 55

Southern Regional Education Board Initiatives..................... 56

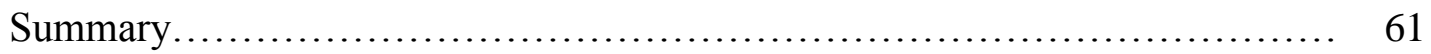

Chapter Three - Methods.................................................... 64

Research Design...................................................... 64

Population and Sample................................................. 65

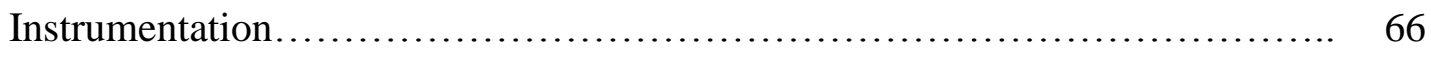

Bolman and Deal's Leadership Orientation (Other) Survey ............. 67

Data Collection Procedures............................................... 69

Data Analysis.......................................................... 70

Anonymity and Confidentiality......................................... 73

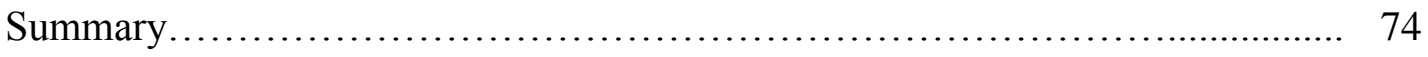




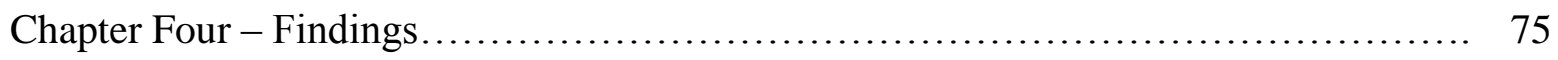

Findings................................................................. 75

Respondents....................................................... 75

Reliability of Survey Instrument....................................... 77

Analysis of Data........................................................ 78

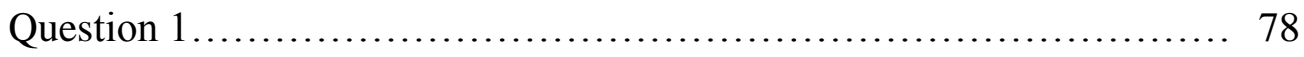

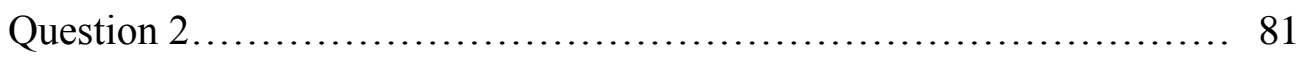

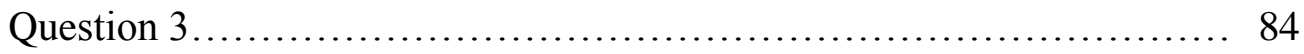

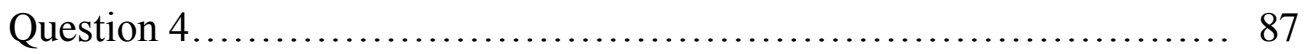

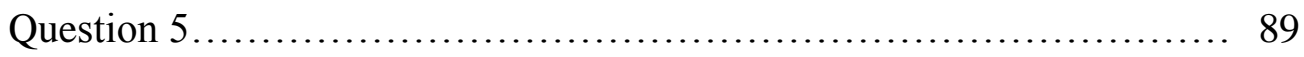

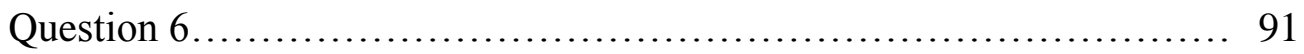

Summary ............................................................... 93

Chapter Five - Conclusions and Recommendations............................... 95

Summary of the Study ................................................. 95

Discussion of Findings............................................... 96

General Patterns of Principals' Leadership Styles............................ 96

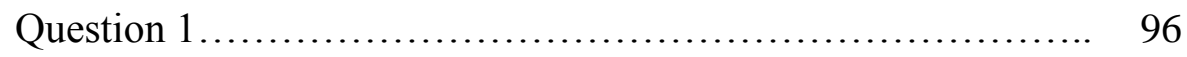

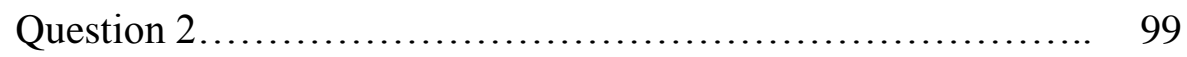

Demographic Effect on Principals' Leadership Styles................... 102

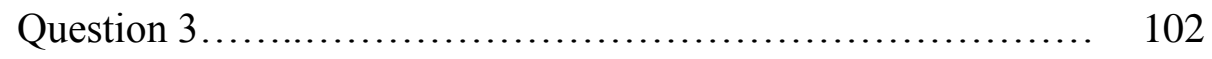

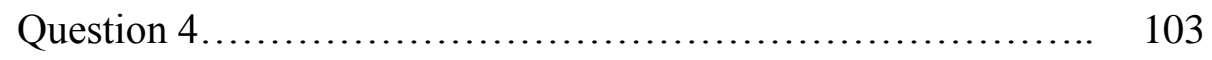

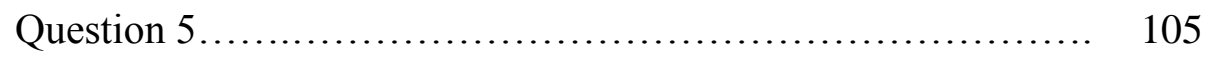

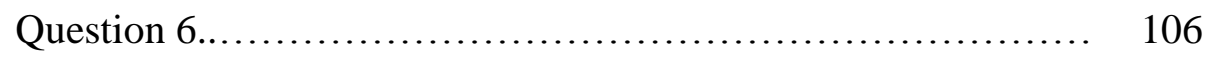

Relationship of Individual Frames to Principal Leadership.............. 107

Conclusions........................................................... 112 
Recommendations..................................................... 113

Recommendations for Practice................................. 113

Recommendations for Future Research........................... 114

References.................................................................... 116

Appendixes............................................................... 128

A. Principal Questionnaire ............................................ 128

B. Bolman and Deal's Leadership Orientation (Other) Survey................. 129

C. Permission to Use Survey Instrument......................................... 130

D. Permission to Use Survey Instrument with Zoomerang Software............ 131

E. Principal Participant Letter.......................................... 132

F. Teacher Participant Letter............................................ 133

G. Follow-up Telephone Conversation Script............................... 134

H. Expedited - IRB Protocol - Exemption................................ 135

I. Permission to Use Bolman and Deal's Four Frame Model Overview......... 136

J. Permission to Use Bolman and Deal's Reliability of Leadership............. 137 Orientation Scales 


\section{TABLES}

2.1 Adequate Yearly Progress (AYP) Extremes................................. 27

2.2 Bolman and Deal's Four Frame Model Overview.................................... 32

3.1 Reliability of Leadership Orientation Scales.................................. 69

4.1 Survey Responses by Demographic Variables................................ 77

4.2 Means and Standard Deviations of Principals' Leadership Frames Rated............ 78 by Teachers

4.3 Frequency Distribution of Principals' Leadership Style by Frame Pattern........... 80

4.4 Differences in Principals' Utilization of Leadership Frames Reported by................. 82 Teachers by School Performance Type

4.5 Frequency Distribution of Principals' Leadership Style by School................. 83 Performance Type

4.6 Difference in Principals' Utilization of Leadership Frames Reported by............ 85 Teachers by Gender

4.7 Frequency Distribution of Principals' Leadership Style by Gender................ 86

4.8 Difference in Principals' Utilization of Leadership Frames Reported by........... 87 Teachers by Administrative Experience

4.9 Frequency Distribution of Principals' Leadership Style by...................... 88 Administrative Experience

4.10 Difference in Principals' Utilization of Leadership Frames Reported by........... 89 Teachers by School Location

4.11 Frequency Distribution of Principals' Leadership Style by..................... 90 School Location

4.12 Difference in Principals' Utilization of Leadership Frames Reported by.......... 92 Teachers by School Size

4.13 Frequency Distribution of Principals’ Leadership Style by School Size........... 93 


\section{Chapter One}

\section{Introduction}

"Whether a school operates effectively or not increases or decreases a student's chances of academic success" (Marzano, Waters, \& McNulty, 2005, p. 3). The demands of the No Child Left Behind Act of 2001 forced on all school systems and schools the necessity of reviewing the end product of their labors - student achievement. In this time of increased accountability due to national and state initiatives, and increasingly global perspectives, it is absolutely essential for schools to have the best possible positive impact on the essence of their existence - the students. Our nation's viability depends on the successful schooling of all students.

\section{Principal Leadership}

Principal leadership is a key factor in establishing the school's focus and mission, providing growth opportunity and support for staff, creating and maintaining a solid organizational structure, and guiding the school's endeavors to maximize student learning. Leadership is directly behind classroom instruction in impacting student achievement and academic performance according to Leithwood, Louis, Anderson, and Wahlstrom (2004). They further indicate that, regardless of the term used to describe a particular leadership style, all accomplish the same two essential objectives for school effectiveness: establishing sound defensible directions for the school and moving people in those directions.

A number of studies confirm the principal's leadership role as a key element in assuring an excellent instructional program for students (Harchar \& Hyle, 1996). This study focuses on the extremely important role principal leadership plays in creating and 
sustaining highly effective schools where student achievement is the primary concern. The importance of this role is substantiated by the past four decades of research on school leadership and its effects on student achievement (Marzano, Waters \& McNulty 2005).

According to the U.S. Senate Committee Report on Equal Educational Opportunity (1977), the principal is the most influential person in the school:

In many ways the school principal is the most important and influential individual in any school. He or she is the person responsible for all activities that occur in and around the school building. It is the principal's leadership that sets the tone of the school, the climate for teaching, the level of professionalism and morale of teachers, and the degree of concern for what students may or may not become. The principal is the main link between the community and the school, and the way he or she performs in this capacity largely determines the attitudes of parents and students about the school. If a school is a vibrant, innovative, child-centered place, if it has a reputation for excellence in teaching, if students are performing to the best of their ability, one can almost always point to the principal's leadership as the key to success. (p. 56)

Richard Andrews states that "gains and losses in students' test scores are directly related to teachers' perceptions of their principal's leadership" (Brandt, 1987, p. 9).

Growth in student achievement, Andrews further maintains, is clearly tied to the degree of positive perception teachers have regarding the quality of their work place. Andrews and Soder (1987) believe research identifies the principal as playing a leading role in the education of students. According to their data, "the school principal is critical in ensuring academic achievement, especially for black and low-income students” (p. 9). 


\section{Principal As Instructional Leader}

Hallinger (1992) indicates that since the 1960s the leadership role of the principal has evolved from manager to instructional leader to transformational leader. A study by the National Conference for State Legislatures (2002) indicates that the "role of school leadership has broadened from performing customary administrative and managerial duties - such as budget oversight, operations and discipline - to include emphasis on other responsibilities such as curriculum development, data analysis and instructional leadership" (p. 4). Nettles and Harrington (2007) indicate that Deal and Peterson (1990) identified instructional leadership "as a way to categorize the activities and responsibilities of principals in relation to classroom instruction" (p. 725).

Hallinger (2003) maintains that during the 1980s instructional leadership was the predominantly identified role for the effective school principal. This role was perceived by many as placing the principal in the all powerful role of educational authority and expert. The 1990s saw the emergence of leadership models born out of reform movements; models that focused more on empowering teachers, sharing leadership, and increasing organizational capacity. Blasé and Blasé (1999) document how principals who are effective instructional leaders encourage open, intellectual exchanges with teachers about instruction, and are attuned to their own growth and improvement. The principal's leadership style was connected by Bogler (2001) to higher job satisfaction for teachers relating to empowerment and self-development opportunities. Harcher and Hyle (1996) documented strategies employed by effective instructional leaders to promote harmony and collegiality in their school communities. 
According to Leithwood and Steinbach (2003), Murphy (2002), and Murphy and Shipman (2003), as cited in Hallinger (2005), at the turn of the twenty-first century, the supreme focus of American education on performance standards had spread globally, emphasizing school accountability and improvement, and the role of the school principal as instructional leader. Today's principals simply cannot ignore this leadership role imperative (Fullan, 2003; Hallinger, 2005).

Leithwood, Louis, Anderson, and Wahlstrom (2004) maintain that "successful leadership can play a highly significant - and frequently underestimated - role in improving student learning" (p. 5). They maintain, based on research covering a wide range of existing schools, principals' leadership has a small but significant effect on student achievement. Additionally, research shows the effect of principal leadership significantly increasing student achievement in schools experiencing difficult circumstances. Further, they indicate that in virtually all instances of a troubled school being turned around, it has been with the intervention of a powerful leader. While other factors may contribute to a school turning around, leadership is still the impetus.

Griffith (1999) in reference to adverse school structural and school population characteristics noted the influence of effective principal leadership styles in lessening these obstacles. In terms of achievement, Mendez-Morse (1991) listed highly supportive and active instructional participation by principals in schools showing success achieved by at-risk students.

Marzano, Pickering, and Pollock (2001) provide evidence of dramatic increases in academic performance of students in effective schools as compared to students in ineffective schools. Marzano, Waters, and McNulty (2005) take this a step further by 
moving from comparing effective with ineffective schools to comparing highly effective with highly ineffective schools. "Although the difference in expected student achievement in "effective" versus "ineffective" schools is dramatic, the difference is even greater when we contrast "highly effective" schools with "highly ineffective" schools -

more specifically, the top 1 percent of schools with the bottom 1 percent" (pp. 3-4). They further maintain that a highly effective principal has the potential to substantially influence students' overall academic achievement.

\section{Statement of the Problem}

This study seeks to identify differences in the leadership styles of principals in high and low performing West Virginia elementary schools based on teacher perceptions. Directly behind classroom instruction, leadership has the most direct impact on student achievement and academic performance (Leithwood, Louis, Anderson, \& Wahlstrom, 2004). Therefore, teacher judgments will provide useful insights in identifying differences in the leadership orientations of principals.

Leadership styles will be identified based on Bolman and Deal's (1984) cognitive frames (structural, human resource, political, and symbolic). The frames give clarity and definition to the role of leadership in organizations as noted in the Definitions of Terms section of this chapter. In addition to identifying differences in the leadership styles, this study will investigate the extent of frame utilization by principals in high and low performing West Virginia elementary schools according to various demographic variables (gender, administrative experience, urban/rural school location, and school size). 


\section{Research Questions/Hypotheses}

Six questions will guide this investigation into differences in teacher perceptions of principal leadership styles in high and low performing West Virginia elementary schools.

Question 1: Based on teacher perceptions, what are the leadership styles of principals in high and low performing West Virginia elementary schools as measured by the four frames (structural, human resource, political, and symbolic)?

Hypothesis: Based on teacher perceptions, there are statistically significant differences in means of leadership styles of principals in high and low performing West Virginia elementary schools.

Question 2: Based on teacher perceptions, what are the differences in the number of frames utilized (none, single, paired, and multiple) by principals in high and low performing West Virginia elementary schools?

Hypothesis: Based on teacher perceptions, there are statistically significant differences in means of the number of frames utilized (none, single, paired, and multiple) by principals in high and low performing West Virginia elementary schools.

Question 3: Based on teacher perceptions, what are the differences in principals' frame utilization (structural, human resource, political, and symbolic) in high and low performing West Virginia elementary schools according to gender?

Hypothesis: Based on teacher perceptions, there are statistically significant differences in means of principals' frame utilization in high and low performing West Virginia elementary schools according to gender. 
Question 4: Based on teacher perceptions, what are the differences in principals' frame utilization (structural, human resource, political, and symbolic) in high and low performing West Virginia elementary schools according to the number of years of administrative experience $(0-5,6-10$, greater than 10$)$ ?

Hypothesis: Based on teacher perceptions, there are statistically significant differences in means of principals' frame utilization in high and low performing West Virginia elementary schools according to years of administrative experience (0-5, 6-10, greater than 10).

Question 5: Based on teacher perceptions, what are the differences in principals' frame utilization (structural, human resource, political, and symbolic) in high and low performing West Virginia elementary schools according to school location (urban/rural)?

Hypothesis: Based on teacher perceptions, there are statistically significant differences in means of principals' frame utilization in high and low performing West Virginia elementary schools according to school location (urban/rural).

Question 6: Based on teacher perceptions, what are the differences in principals' frame utilization (structural, human resource, political, and symbolic) in high and low performing West Virginia elementary schools according to school size (small/medium/large)?

Hypothesis: Based on teacher perceptions, there are statistically significant differences in means of principals' frame utilization in high and low performing West Virginia elementary schools according to school size (small/medium/large). 


\section{Significance of the Study}

Given the West Virginia Department of Education's recognition of: (1) the extreme importance of the role of the school principal as the instructional leader of the school and its impact on student achievement (outlined in West Virginia Department of Education, WV Achieves - Framework for High Performing $21^{\text {st }}$ Century School Systems, 2006), and (2) the department's focus on developing principal leadership skills (West Virginia Department of Education, West Virginia Institutes for $21^{\text {st }}$ Century Leadership, 2008), this study provided data for potential use by the state department of education in planning and developing future initiatives to improve principals' leadership skills and ultimately improve student achievement for the students of West Virginia. In addition, this study provided data that can be utilized by higher education institutions to plan and develop leadership studies course work for aspiring current and future administrators.

\section{Limitations of the Study}

1. This study focused solely on the impact of principals' leadership styles on student achievement and does not consider other factors, for example, teachers' classroom management and instruction.

2. This study employed quantitative analysis of data only.

3. Data used to determine high and low performing West Virginia elementary schools focused only on the percent of students in the "All Students" subgroup making Adequate Yearly Progress (AYP) in Mathematics and Reading/Language Arts on the 2007-08 WESTEST. 
4. The study is limited by the use of only one instrument to measure principals' leadership styles.

5. This study focused on the perceptions of only one stakeholder group in the school, the teachers.

6. Staff changes may have occurred in (principals and teachers) in identified high and low performing schools for this study.

7. There was a low return rate of teacher responses despite the extended time span for data collection, October, 2008 through January, 2009.

8. This study did not take into consideration the total length of time the principal has served as leader of a school, as opposed to the specific range of experience in the school identified in this study.

\section{Assumptions}

1. Teachers can accurately assess the principal's leadership.

2. The responses received from participating teachers accurately reflect their professional opinions regarding the principal's leadership.

3. Teacher participants answered questions openly and honestly.

4. The Bolman and Deal (1990) Leadership Orientations Survey is a valid assessment of principals' leadership styles.

\section{Definitions of Terms}

The following key terms are defined to provide clarity for understanding the thrust and intent of this study.

Structural Frame -The organization “emphasizes goals, specialized roles, and formal relationships," assigns responsibilities and makes "rules, policies, procedures, and 
hierarchies" in order to unify the varied activities of the organization (Bolman \& Deal, 2003, p. 14).

Human Resource Frame -Through this lens the organization is shaped and designed to meet the needs of individuals; that is, aligning jobs with workers' needs. The goal is to facilitate individuals to accomplish their assigned tasks in a manner that imparts a positive sense about it.

Political Frame - This frame identifies the organization as having competitions for scarce resources and being fraught with conflicts over individual and group needs within the organization. Existence in this frame depends on the ability to negotiate, bargain, and compromise.

Symbolic Frame - "It sees organizations as cultures, propelled more by rituals, ceremonies, stories, heroes, and myths than by rules, policies and managerial authority" (Bolman \& Deal, 2003, p. 15). These rituals, ceremonies, and stories give credence to the organization's purposes, and engender a sense of belonging.

No Frame Leadership - Principals who are perceived by teachers as not implementing any of the four leadership frames - structural, human resource, political, or symbolic (Bolman \& Deal, 1992).

Single-Frame Leadership - Principals who are perceived by teachers as implementing only one of the four leadership frames - structural, human resource, political, or symbolic (Bolman \& Deal, 1992).

Paired-Frame Leadership - Principals who are perceived by teachers as implementing two of the four leadership frames - structural, human resource, political, or symbolic (Bolman \& Deal, 1992). 
Multiple-Frame Leadership - Principals who are perceived by teachers as implementing more than two of the four leadership frames - structural, human resource, political, or symbolic (Bolman \& Deal, 1992).

Teachers - The certified professional staff assigned to a school for delivering instructional services to students on a regular basis.

Elementary Schools - West Virginia State Board of Education Policy 2320, Section 4.2, defines elementary schools in West Virginia as schools containing any grade configuration of grades K-7, but not grade 8 .

Level of Student Academic Achievement - The academic progress of students within a school as measured on the annual summative assessment for schools in West Virginia - the WESTEST.

WESTEST - The West Virginia Educational Standards Test (WESTEST) is a customized, criterion referenced test aligned to West Virginia Content Standards and Objectives (CSOs). It is administered to students in grades 3-8 and grade 10 annually.

Adequate Yearly Progress (AYP) - The annual measurement of student(s) academic progress that, based on state defined cut scores, identifies individual student's test performance as falling into one of the following categories: Novice, Partial Mastery, Mastery, Above Mastery, and Distinguished. Students scoring in the last three categories are considered to have met AYP.

Reading Math Index (RMI) - An index developed for this study that represents the combined totals of Reading and Mathematics percentage of students making adequate yearly progress (AYP) on the West Virginia Educational Standards Test (WESTEST). 
High performing Elementary Schools - Schools with a total RMI of 183.6 to 200 as translated from the percent of students in a school meeting AYP in both mathematics and reading on the 2007-2008 WESTEST.

Low performing Elementary Schools - Schools with a total RMI of 98.4 to 135.7 as translated from percent of students in a school meeting AYP in both mathematics and reading on the 2007-2008 WESTEST.

Urban - Schools located in cities or towns with a population greater than 2500 (Federal Register Part IV Department of the Commerce Bureau of the Census, 2001).

Rural - Schools located in cities, towns, or communities with a population fewer than 2500 (Federal Register Part IV Department of the Commerce Bureau of the Census, 2001).

Small/Medium/Large Elementary Schools - For purposes of this study schools will be divided into small, medium and large based on 2007-2008 enrollment data for elementary schools in West Virginia. Elementary school enrollments in West Virginia range from 49 students to 790 students (School Type, Size All Grades School Year: 2008-09 - West Virginia Department of Education). School sizes for this study are as follows: Small (49-200 students) - 117 schools; Medium (201-400 students) - 193 schools; and Large (401-781 students) - 85 schools.

\section{Organization of the Study}

This study is organized in the following manner. Chapter One introduces the study outlining its purpose, significance, and organizational structure. Chapter Two presents a review of the related literature relative to principal leadership styles, the four leadership frames of Bolman and Deal, and student achievement. Chapter Three 
delineates the research design and the methods used in completing this study: selection of the sampling population, sampling procedures, data gathering instruments, data collection procedures, and data analysis procedures. An analysis of the data and a discussion of the findings are presented in Chapter Four. Chapter Five contains the summary, conclusions of the study, recommendations of the study, and recommendations for future research. The study concludes with references and appendixes of pertinent information.

\section{Summary}

Chapter One introduces the purpose and importance of this study. It identifies the variables the study reviewed in the process of determining whether there is a significant relationship between the principals' leadership styles and student achievement in 60 identified high and low performing West Virginia elementary schools. Limitations of the study, assumptions about the processes and procedures of the study, key terms utilized in the study, and the organizational outline of the study are also included in this chapter. 


\section{Chapter Two}

\section{Literature Review}

Chapter Two is a review of literature germane to the variables of this study: principals' leadership styles and principals' leadership relative to student achievement. More specifically, this chapter investigates literature relative to the study of leadership (traits, behavior, situational/contingency, and transformational); the conceptual framework used to determine principals' leadership styles for this study (Bolman and Deal's four-frame leadership orientations model and relative studies); principals' leadership and student achievement (reports and legislation impacting principal leadership and student achievement, the Effective Schools Movement, and studies of principals' leadership and student achievement); and $21^{\text {st }}$ century initiatives for improving principals' leadership (Institute for Educational Leadership and Southern Regional Education Board).

\section{Study of Leadership}

Leadership, according to Yukl (2002), is a "social process in which a member or members of a group or organization influence the interpretation of internal and external events, the choice of goals or desired outcomes, organization of work activities, individual motivation and abilities, power relations, and shared orientations" (as cited in Hoy \& Miskel, 2005, p. 377). Leaders are expected to "persuade and inspire rather than coerce and give orders ... and to produce cooperative effort and to pursue goals that transcend narrow self-interest” (Bolman \& Deal, 2003, p. 337). Therefore, leadership exists solely in relationships of individuals within an organization. 
Research on effective leadership has evolved through a variety of perspectives:

(1) the personal traits of leaders themselves (Traits Model); (2) the relationship between what leaders do and how employees react emotionally and behaviorally (Behavior Model); (3) the leadership approaches utilized in different situations and environments (Situational/Contingency Model); and (4) the inspiration of employees to abandon selfinterest for the good of the organization (Transformational Model). As the study of leadership evolved from the early1900s on, researchers have sought to identify leadership behaviors found in effective leaders (Mendez-Morse, 1992).

\section{The Traits Model}

From the early 1900s through the 1950s, leadership research focused on identifying traits of leaders and non-leaders to determine who were likely to become leaders. The underlying assumption of this model is that leaders are endowed with certain physical, intellectual, social, and personal characteristics. As cited in Hoy and Miskel (2005), Bass (1990) noted that during this period of leadership research, leaders were viewed as superior individuals who "possessed qualities and abilities that differentiated them from people in general" (p. 378). Personal traits associated with leadership are: capacity, achievement, responsibility, participation, status, and situation (Stogdill, 1974 as cited in Mendez-Morse, 1992). Certainly, it would be difficult to imagine one person possessing all of these traits.

More recent studies of the Traits Model have moved away from focusing on distinguishing traits of leaders and non-leaders (followers) to determining relationships between leaders' traits and leadership effectiveness in different types or organizational 
settings and situations. In more recent studies, Stogdill (1981), as cited in Hoy and Miskel (2005), identified the following leadership traits in effective leaders: a strong drive for responsibility and task completion, vigor and persistence in pursuit of goals, venturousness and originality in problem solving, drive to exercise initiative in social situations, self-confidence and sense of personal identity, willingness to accept consequences of decision and action, readiness to absorb interpersonal stress, willingness to tolerate frustration and delay, ability to influence other persons' behavior, and capacity to structure interaction systems to the purpose at hand. (pp. 379-380)

However, as pointed out by Mendez-Morse (1992) researchers have concluded that there is no single trait that separates leaders from non-leaders.

\section{The Behavior Model}

During the 1950s and 60s theorists began to study actions and methods used by leaders in reaching their goals. This approach conceptualized leadership as behavioral, and sought to determine key patterns of behavior that resulted in effective leadership.

Douglas McGregor, as noted in Bolman and Deal (2003) and Shafrtiz, Ott, and

Jang (2005), looked at how leaders viewed their employees, described as Theory $\mathrm{X}$ and Theory Y. Theory X leaders believe employees are lazy, uncooperative, lacking good work habits, and motivated primarily by money. On the contrary, Theory Y leaders believe that subordinates have positive attitudes, are cooperative, and work diligently. Theory X fails to discover the potentialities of its workers. Theory Y creates an environment that encourages commitment to organizational goals while providing opportunities to demonstrate initiative, ingenuity, and self-direction in achieving them. 
Leadership studies conducted by the Ohio State University beginning in the 1940s identified structure and consideration as key elements in organizational success. Initiating structure, according to the study, delineates the relationship between the leader and subordinates within the organization as well as defines organizational procedures and channels of communication. Consideration focuses on leader behaviors that engender trust and respect between the leader and subordinates. "To neglect initiation of structure limits the leader's impact on the organization; to ignore consideration reduces the satisfaction of the subordinates" (Hoy \& Miskel, 2005, p. 387). Research findings are inconclusive regarding which element (initiating structure or consideration) most influences satisfaction and productivity within the organization.

Similar leadership studies conducted by the University of Michigan provided the basis for the Managerial Grid model developed by Robert Blake and Jane Mouton (1985). It identifies five leadership styles that represent different combinations of concern for people and concern for task. Managers who simultaneously scored high in both areas (concern for people and concern for task) were determined to be "ideal managers" who successfully integrate people and tasks and yield high levels of production in the organization (Bolman \& Deal, 2003).

\section{The Situational/Contingency Model}

According to Hoy and Miskel (2005), during the 1960s and 1970s Fiedler (1967) devised the first major theory of contingency leadership entitled, Least Preferred Coworker Theory (LPC). This theory considers three aspects: leadership style, situational control, and effectiveness. Leadership style in Fielder's theory determines the degree to which an individual is task-motivated or relationship-motivated based on the LPC rating. 
In regard to situational control, the study considered three factors: position power (conferred leader power), task structure (the extent of specification of goals and methods), and leader-member relationship (the degree of acceptance of the leader by members). The effectiveness component of this study focused solely on the degree to which tasks are accomplished in the organization. Results of studies of Fielder's contingency model yielded only partial support for the theory.

The Path-Goal Theory developed by Robert House (1971) in the 1970s is based on the expectancy theory of motivation. "Its overall proposition is that subordinate satisfaction and individual and work unit effectiveness increase as leaders engage in behaviors that complement the task environments and subordinates' abilities and compensate for deficiencies" (Hoy \& Miskel, 2005, p. 394). The manager's job is viewed as coaching or guiding workers to choose the best paths for reaching their goals. There are five leadership behaviors associated with this theory: path-goal clarifying (clarifies performance goals, tasks, standards, expectations, and rewards and punishments), achievement-oriented (encourages excellence, challenges, and shows confidence), supportive (creates a positive work environment physically and psychologically), value-based (focuses on subordinates' self-efficacy), and shared (shares leadership with subordinates). This theory is believed to be limited "in not dealing with emergent informal leadership, political behavior of leaders, leadership as it affects several levels of administrators or subordinates in organizations, or leadership for change" ( $p$. 395).

The Hersey-Blanchard situational leadership model as described by Marzano, Waters, and McNulty (2005) requires leaders to adapt their leadership behaviors to meet 
the level of "maturity" of employees. The level of "maturity" of the employee is defined as their ability and willingness to perform organizational tasks. There are four combinations of ability and willingness: unable and unwilling; unable and willing; able and unwilling; and able and willing. Each combination requires a specific leadership behavior to engender productivity on the part of the employee. Those behaviors are described as telling, participating, selling, and delegating and are associated respectively with the above stated four combinations of ability and willingness. This model is definitely associated with the human resource leadership frame because it focuses on the relationships between leaders and subordinates (Bolman \& Deal, 2003).

"The dearth of attributes consistently associated with effective leadership reinforces the argument that leadership varies with the situation" (Bolman \& Deal, 2003, p. 342). Therefore, the ability of the leader to ascertain the environment of the organization and adapt behaviors to address the needs of employees and situations is essential for leadership success (Marzano, McNulty, \& Waters, 2005).

\section{The Transformational Model}

The late 1970s and 1980s saw the emergence of the transformational leadership model. The 1990s saw the beginning of school restructuring in the United States. Restructuring was attributed to growing concerns that schools were not effectively educating students. The transformational leadership model has been identified as a reform model with potential for addressing school restructuring initiatives, and it has been identified as the most widely used of the reform models (Marks \& Louis, 1997).

Transformational leadership's main focus is growing the innovative capacity of the organization to determine its mission, in addition to developing changes in teaching 
and learning strategies needed to accomplish the mission. The transformational leadership model emphasizes understanding the needs of individuals and motivating them through support and intellectual stimulation rather than control and coercion (Conley \& Goldman, 1994; Hallinger, 2003). Hallinger (2003), Leithwood (1994) labeled this leadership approach as 'second order' change because it goes beyond a basic understanding of best practices to focusing on changing the normative practices and structures of the organization.

Transformational leaders motivate followers by raising their consciousness about the importance of organizational goals and by inspiring them to transcend their own self-interest for the sake of the organization. In their relationships with followers, this theory posits, transformational leaders exhibit at least one of these leadership factors: idealized influence, inspirational motivation, intellectual stimulation, and individualized consideration. (Marks \& Printy, 2003, p. 375) According to Hallinger (2003), Leithwood and Jantzi (1999) conducted a study of principal leadership that found "transformational leadership had strong direct effects on school conditions (.80) which, in turn, had strong direct effects on classroom conditions (.62)” (p. 339). In regard to student outcomes, transformational leadership was instrumental in guiding teachers' thinking in implementing new reform initiatives, thus affecting student achievement (Bogler, 2001; Day, Harris \& Hadfield, 2001; Fullan 2002 - as cited in Hallinger, 2003).

A number of educational scholars have identified transformational leadership as the vehicle to bring about reforms necessary for school restructuring. Transformational leadership gets at the issues of identifying and resolving problems through the 
collaborative efforts of the principal, teachers, and other stakeholders. This is all done with the intent of enhancing school performance outputs (Hallinger, 1992). The obvious fact is that teachers through classroom interactions with their students know best how they learn. Therefore, teachers need greater decision making power and involvement in regard to their curriculum and instructional practices (Hallinger, 1992).

Jackson (2000), as cited in Hallinger (2003), concludes that uncertainty increases as the transformational leader involves more people in the decision-making process. The principal must understand that uncertainty and ambiguity are natural occurrences that must be worked with and tolerated. Uncertainty and ambiguity are inevitable in the successful implementation of Bolman and Deal's human resource frame (empowering others), and in the political frame (managing conflict that arises over competition for scarce resources).

\section{The Conceptual Framework for This Study}

This study addresses the relationship between leadership styles of principals in high and low performing West Virginia elementary schools as perceived by teachers in those schools. This section presents rationales for components considered in this study: teachers' perceptions of principals' leadership styles, elementary schools, and high and low performing schools. However, prior to discussing these components, it is necessary to address the importance of school culture and its impact on school outcomes. School culture affects all the components in this study and will be discussed with each.

\section{School Culture}

The culture of a school is evidenced in its beliefs, values, traditions, and rituals, which emerge over a period of time as people work together, solve problems together, 
confront barriers together, and celebrate successes together. Culture literally touches all facets of school life: school mission, teacher expectations, and opportunities for students and staff to learn (Hoy \& Miskel, 2005; Marzano, Waters, \& McNulty, 2005; Peterson \& Deal, 1999).

Peterson and Deal (1999) identify elements of positive, successful school culture

as:

- A mission focused on student and teacher learning

- A rich sense of history and purpose

- Core values of collegiality, performance, and improvement that engender quality, achievement, and learning for everyone

- Positive beliefs about the potential of students and staff to learn and grow

- A strong professional community that uses knowledge, experience, and research to improve practice

- An informal network that fosters positive communication flows

- Leadership that balances continuity and improvement

- Rituals and ceremonies that reinforce core cultural values

- Stories that celebrate successes and recognize heroines and heroes

- A physical environment that symbolizes joy and pride

- A widely shared sense of respect and caring for everyone

"A school administrator is an educational leader who promotes the success of all students by advocating, nurturing, and sustaining a culture and instructional program conducive to student learning and staff professional growth" (Council of Chief State School Officers, 1996, p. 12). According to Wang, Haertal, and Walbert, (1993), school 
culture significantly impacts learning outcomes by providing an environment that promotes and sustains effective teaching and learning practices. Thus, the role of the principal is vital in creating a school culture that produces positive outcomes for both students and teachers.

"Although a culture is a by-product of people working in close proximity, it can be a positive or negative influence on a school's effectiveness" (Marzano, Waters, \& McNulty, 2005, p. 47). An effective principal focuses on building a school culture that positively influences teachers, who ultimately influence students. Leithwood and Riehl (2003) indicate that:

Leaders act through and with other people. Leaders sometimes do things, through words or actions, that have a direct effect on the primary goals of the collective, but more often their agency consists of influencing the thoughts and actions of other persons and establishing policies that enable others to be effective (p. 8). From their meta-analysis research, Marzano, Waters, and McNulty (2005) define the responsibility of culture as the extent to which the leader engenders shared beliefs and a sense of community and cooperation among staff. They further identify behaviors associated with this responsibility: "promoting cohesion among staff, promoting a sense of well-being among staff, developing an understanding of purpose among staff, and developing a shared vision of what the school could be like" (p. 48). The importance of developing shared vision in schools has been advocated routinely by researchers both in and outside of education (Blanchard, 1996; Kotter, 1996; Kouzes \& Posner, 1996; Schlecty, 1997; Senge, 1990). 
Marzano, Waters, and McNulty (2005) further indicate that a prevalent theme in research on principal leadership deals with the leader perpetuating a school culture that indirectly affects improving student achievement. "Research on school improvement has shown that schools in which there is a clear, academically oriented mission are better able to make decisions in the interests of students and to allocate resources toward the improvement of teaching and learning” (Hallinger \& Leithwood, 1998, p. 140). The school leader who is attentive to nurturing and developing the school's culture will have a great deal of influence over the school's ability to improve (Peterson \& Deal, 1998).

Barth (2001) maintains that the most important and difficult job facing the principal seeking to effect school reform and improvement is to change the prevailing school culture. "Ultimately, a school's culture has far more influence on life and learning in the schoolhouse than the state department of education, the superintendent, the school board, or even the principal can ever have" (p. 7).

According to Kotter and Cohen (2002) as presented in Bolman and Deal (2003), successful leaders give attention to nurturing and sustaining a positive organizational culture. The four frames, each with its own unique organizational focus, play a crucial role in developing culture in the following manner: structure - by charting responsibilities in the organization and forming focus groups to analyze structures within the organization; human resource - by improving safety and security, and by providing trainings in communication, conflict management, participation, and teaming; political by providing arenas for negotiating and networking, by doing damage control, uniting members against external threats, building coalitions, and negotiating; and symbolic - by continually developing the organization's symbols, ceremonies, and stories (p. 426). 


\section{Teacher Perceptions of Principal Leadership Styles}

Teachers live school culture every day. Unlike the changing clientele of a business or a medical community, school culture involves daily interaction with the same people. Interaction among fellow teachers, students, and principals on a regular basis provides opportunity for frequent observations of actions and behaviors. By virtue of this close proximity, interactive working relationship, teachers hold the best position to judge and assess principals' leadership skills. Students, parents, and community members are less aptly positioned to keenly observe leadership.

This study does not utilize principals' self reporting in the data collection process because it can reflect inflated and biased view points. Adams, Soumerai, Lomas, and Ross-Degnan (1999), in a study to determine the impact of response bias on the validity of self-reports as measures of the quality of health care, found the extent of bias in self reporting to be substantial. "Thus, the increasing reliance on self-reports as a measure of quality of care appears to produce gross over-estimation of performance” (p. 190). Donaldson and Grant-Vallone (2002), in their paper outlining "a conceptual framework for understanding factors that influence the motivation of an employee to bias his or her response to questions," conclude that self reporting bias often endangers "the validity of research conducted in business settings and thus hinder the development of theories of organizational behavior" (p. 245). Therefore, the perceptions of teachers will be used to assess the leadership styles of elementary school principals considered in this study.

\section{West Virginia Elementary Schools}

First, and foremost, elementary schools are recognized as providing the crucial foundation blocks for all formal learning in our society. "Throughout the elementary 
years, the skills for future learning, the child's attitude about school, and most importantly, the child's view of self as a learner are developed" (WVDE, 2006, p. 4).

Elementary schools possess the largest segment of student population in West Virginia's public schools. There are 135,324 students in grades PreK-5, 65,031 students in grades 6-8, and 82,681 students in grades 9-12. Elementary schools in West Virginia represent the largest programmatic group of schools in West Virginia: 395 elementary, 157 middle, and 120 high schools (WVDE Website). With more than double the number of middle schools and more than triple the number of high schools, elementary schools in West Virginia have the greater population of principals and teachers for sampling purposes.

\section{West Virginia High and Low Performing Elementary Schools}

There are high and low student achievement performance extremes among the 395 elementary schools in West Virginia. This study focuses on the top 30 (high performing) and the bottom 30 (low performing) elementary schools in West Virginia. Table 2.1 displays those extremes for the top 30 and bottom 30 schools as measured on the 2007-2008 WESTEST, West Virginia's summative assessment of student achievement. The table indicates the percent ranges of students making and not making adequately yearly progress (AYP) in those high and low performing schools.

The foundation of a high performing elementary school is the quality of its culture (Peterson \& Deal, 1998). The culture of a high performing school demonstrates appreciation for the staff and their commitment to a shared sense of purpose, collegiality, hard work, responsibility and commitment to learning and teaching. "A high performing elementary school welcomes all learners into a positive, challenging, supportive, and 
respectful school where they will be recognized as unique individuals and provided the contagious spark to fuel a lifelong love for learning" (WVDE, 2005-2006, p. 3).

Table 2.1

Adequate Yearly Progress (AYP) Extremes

\begin{tabular}{lcc}
\hline Performance & $\begin{array}{c}\text { Percent range of } \\
\text { students making AYP }\end{array}$ & $\begin{array}{c}\text { Percent range of } \\
\text { students not making AYP }\end{array}$ \\
\hline High & $91.8-99.0$ & $1.0-8.2$ \\
Low & $49.2-67.8$ & $32.2-50.8$ \\
\hline
\end{tabular}

High performing schools generally possess a strong positive culture in which there is a clear understanding of what is important, an attitude of caring and concern, and a strong commitment to helping students become productive learners. "Schools with strong cultures of efficacy and trust provide higher levels of student achievement whereas schools with custodial cultures impede the socio-emotional development of students" (Hoy \& Miskel, 2005, p. 175-176).

In contrast, low performing schools have a culture that is vastly different from high performing schools, and it is often described as toxic and unproductive. In low performing schools, the focus is on the adults rather than the students. A sense of hopelessness and failure predominates. Discussions aimed at school improvement are thwarted or dismissed by negative staff members who seek to maintain the status quo (Peterson \& Deal, 1998; West Virginia Department of Education, 2006).

\section{Bolman and Deal's Four-Frame Leadership Orientation Model}

The conceptual framework for the principals' leadership styles component of this study is the Bolman and Deal four-frame leadership orientation model. Several of the 
leadership models discussed in the Study of Leadership section of this chapter are referenced in their presentation of theories on leadership and organizational life. Bolman and Deal (2003) have consolidated "major schools of educational thought" into their four frames of leadership orientation - structural, human resource, political, and symbolic ( $\mathrm{p}$. 12).

Bolman and Deal (2003) provide useful knowledge and practical advice about the complexities of organizational life. Through their research and study of organizations they have devised four perspectives or frames of effective leadership behavior. The four frames were first described in the early 1980s (Bolman \& Deal, 1984).

According to Goldman and Smith (1991), Bolman and Deal's framework of organizational leadership is most appropriate for defining schools, as all four frames may appear in the school context. Schools are people oriented - a people business; thus, in essence, they are a human resource. The symbolic context of a school is evidenced by the public's identity and familiarity with it. Diversity of populations (students, parents, community, and staff) brings to light the political aspects of schools.

Bolman and Deal provide guidance for leaders in analyzing and understanding the complexities of organizational life and how best to utilize the four frames in leading an organization. Further, they identify benefits and advantages as well as issues and problems associated with each frame (Bensimon, 1987; Goldman \& Smith, 1991; Bolman \& Deal, 2003).

The structural frame is the oldest and most widely used method of viewing organizations. This frame views the organization as a "factory," and it "emphasizes goals, specialized roles, and formal relationships" (Bolman \& Deal, 2003, p. 14). The 
structure of an organization is designed to fit the environment and technology unique to each individual organization's needs. In order to bring the varied activities of the organization into unity, the organization must create "rules, policies, procedures, and hierarchies" (p. 14). In order to remain vibrant and viable, an organization must embrace a mode of perpetual change to meet the constantly changing nature of its circumstances. Neglecting the structural frame will lead to misdirection of the organization's time and energy.

The human resource frame sees the organization as a "family." The organization is "made up of individuals with needs, feelings, prejudices, skills, and limitations" (Bolman \& Deal, 2003, p. 14). Through this lens the organization is shaped and designed to meet the needs of individuals; that is, aligning jobs with workers' needs. The goal is to facilitate individuals in accomplishing assigned tasks in a manner that yields positive benefits for them and in the long-run benefits the organization.

This frame advocates investing in and empowering people. The organization invests in development of its people through providing training and educational opportunities. Empowering people means providing information, being supportive, and giving them opportunities for autonomy, influence and intrinsic rewards. Hence, a good workplace focuses on treating all personnel well (Bolman \& Deal, 2003).

The political frame views the organization as "arenas, contests, and jungles" (Bolman \& Deal, 2003, p.14). This frame identifies the organization as having competitions for scarce resources and being fraught with conflict because of varied individual and group needs. Existence depends on one's ability to negotiate and compromise. 
The most important decisions in the political frame are about allocating limited resources. Conflict erupts in the acquisition of these scarce resources, making power the most important asset. This frame "does not view conflict as something that can or should be stamped out" (Bolman \& Deal, 2003, p. 197). In fact, this frame views conflict as being natural and unavoidable. Interestingly, according to research presented in Bolman and Deal (2003), conflict can be good or bad for the organization depending on what conflict management strategies are utilized.

Bolman and Deal (2003) indicate that "organizational change and effectiveness depend on managers' political skills" (p. 220). To be a successful leader in the political frame one must be able to set an agenda, know and map the political terrain, build coalitions by networking, and be able to bargain and negotiate.

The symbolic frame views organizations as "theaters." "It sees organizations as cultures, propelled more by rituals, ceremonies, stories, heroes, and myths than by rules, policies and managerial authority" (Bolman \& Deal, 2003, p. 15). As "theaters" - drama - the organization is viewed by how it appears. These dramas fortify faith in the organization's purposes, and engender a sense of belonging (being part of the team) for its people. Teamwork is strengthened in the organization when people have events that give identity and foster unity in the organization.

In this frame one discovers the soul, spirit, and heart of the organization. The organization's mission, goals, and belief systems are embedded in its people through meaningful rituals and stories. Problems arise when the rituals and ceremonies lose their power and efficacy (Bolman \& Deal, 2003). 
This symbolic frame as identified in Bolman and Deal (2003) is the most difficult frame to define and clearly articulate. However, this does not diminish the critical role it plays in the successful operation of the organization. To ignore this frame would be to ignore the soul of the organization, thereby creating an organizational environment that lacks identity.

Bolman and Deal (1991, 2003) and Cunningham and Gresso (1993) indicate that the school culture is most evident in the symbolic nature of social interactions that take place within its confines. Bolman and Deal (2003) refer to the culture perspective of organizations as the symbolic frame. They maintain that the symbolic frame is based on the following concept of organizational behavior: the most important aspect of organizational events is not the events, but rather the meanings they hold. In many cases, meanings take precedence in importance over facts. Hoy and Miskel (2005) conclude from the literature on organizational culture that "much of what occurs in schools must be interpreted in the context of the school's culture; often what is said or done is not nearly as important as its symbolic significance" (p. 175).

Hanson (2001) maintains that outward displays of a school's culture (artifacts and symbols) reflect its cultural priorities. Much of the school's culture can be envisioned through its: "artifacts, rites, rituals, and ceremonies related to assemblies, faculty meetings, athletic contests, community activities, cafeteria, report cards, awards and trophies, lesson plans, and the general décor of the school” (Hoy \& Miskel, 2005, p. 173).

Table 2.2 presents an overview of the four-frame leadership model. It presents images of the organization through metaphors, concepts, leadership images, and challenges for each of the frames. 
Bolman and Deal (2003) maintain that any one of the four frames used exclusively to address organizational existence would be inadequate. "Each of the frames offers a distinctive image of the leadership process. ... but none is right for all times and seasons" (p. 348). They further maintain that every leader can be identified with at least one of the four frames, and generally favors one frame over the others.

Table 2.2

Bolman and Deal's Four Frame Model Overview**

\begin{tabular}{|c|c|c|c|c|}
\hline & Structural & $\begin{array}{l}\text { Human } \\
\text { Resources }\end{array}$ & Political & Symbolic \\
\hline $\begin{array}{l}\text { Metaphor for } \\
\text { Organizations }\end{array}$ & $\begin{array}{l}\text { Factory or } \\
\text { machine }\end{array}$ & Family & Jungle & $\begin{array}{l}\text { Carnival, temple } \\
\text { theater }\end{array}$ \\
\hline Central Concepts & $\begin{array}{l}\text { Rules, roles, goals, } \\
\text { policies, technology, } \\
\text { environment }\end{array}$ & $\begin{array}{l}\text { Needs, skills, } \\
\text { relationships }\end{array}$ & $\begin{array}{l}\text { Power, conflict, } \\
\text { competition, } \\
\text { organizational } \\
\text { politics }\end{array}$ & $\begin{array}{l}\text { Culture, meaning, } \\
\text { metaphor, ritual, } \\
\text { ceremony, } \\
\text { stories, heroes }\end{array}$ \\
\hline $\begin{array}{l}\text { Image of } \\
\text { Leadership }\end{array}$ & Social architect & Empowerment & Advocacy & Inspiration \\
\hline $\begin{array}{l}\text { Basic } \\
\text { Leadership } \\
\text { Challenge }\end{array}$ & $\begin{array}{l}\text { Attune structure to } \\
\text { task, technology, } \\
\text { environment }\end{array}$ & $\begin{array}{l}\text { Align } \\
\text { organization } \\
\text { and human } \\
\text { needs }\end{array}$ & $\begin{array}{l}\text { Develop an } \\
\text { agenda and } \\
\text { power base }\end{array}$ & $\begin{array}{l}\text { Create faith, } \\
\text { beauty, meaning }\end{array}$ \\
\hline
\end{tabular}

Note. Adapted from Reframing Organizations: Artistry, Choice, and Leadership (p. 16),

by L.G. Bolman and T. E. Deal, 2003, San Francisco, CA: Jossey-Bass. Copyright 2003

John Wiley \& Sons, Inc. Adapted with permission of the author (Appendix I).

The four frames provide a structured way of viewing organizational operations.

A leader who possesses a sound understanding of the intricacies and expectations of each frame, and who is able to identify the frame(s) from which individuals and groups operate, can potentially maximize successful responses by devising appropriate strategies to address situations and issues (Bolman \& Deal, 2003). 


\section{Bolman and Deal - Multi-Frame Leadership}

Bolman and Deal (1991) assert that managers and leaders often are not well equipped with ideas and responses for dealing with the varied organizational problems and challenges they face. These limited perspectives narrow the field of response options and diminish the potential for success. Leaders need multiple lenses and skills for looking at old problems in new ways. Successful managers understand that organizational progress is a process of framing and reframing through multiple lenses. They must reframe until the organizational blurs are in focus and clear. "They do this by using more than one frame, or perspective, to develop both a diagnosis of what they are up against and strategies for moving forward" (Bolman \& Deal, 2003, p. 15). Successful leaders are comfortable moving between frames (Bensimon, 1987; Goldman \& Smith, 1991; Bolman \& Deal, 2003).

Twenty-first-century principals must employ a variety of leadership approaches (Bensimon, 1990; Bolman \& Deal, 1991, 1992). Bolman and Deal (1991, 1992, 2003) refer to this as multi-framed leadership. Studies indicate that effective leaders use multiple frames in order to view situations from a variety of perspectives (Bolman $\&$ Deal, 1991, 1992). Utilizing multiple frames in assessing issues provides a more comprehensive view in determining solutions to address those matters. The ability to employ multi-frame thinking as opposed to no-frame or single-frame thinking strengthens principals' problem-solving skills and enhances their ability to develop creative solutions, according to Bolman and Deal (1992).

Bolman and Deal (1992) conducted a study of the relationship between management and leadership for school administrators in the United States and Singapore. 
Both interviews and surveys were used by researchers to gather data regarding 50 Florida principals, 30 Oregon principals and central office personnel, and 274 school administrators from Singapore. The study determined that all four frames were positively associated with measures of effectiveness among United States and Singapore administrators. It further found that effective leaders in Singapore were oriented toward symbolic and structural leadership orientations while effective leaders in the United States were oriented toward human resource (people), political, and symbolic orientations. The results suggested that in both Singapore and the United States, the ability to use multiple frames was crucial in the leadership and managerial effectiveness of principals. The study further found the human resource and political frames to be significant positive predictors of success for leaders and managers.

\section{Bolman and Deal's Four Frame Leadership Orientation Model in Action}

What do Bolman and Deal's four frames look like in the school setting? Perhaps the best response to that question is to apply the frames to actual problems principals face. Each scenario below is followed by a principal's potential response utilizing each frame (structural, human resource, political, and symbolic) with elaboration on how the principal's response meets the frame's identified characteristics.

Scenario I - A teacher is not turning in lesson plans in a timely manner.

Structural Frame: The principal posts a signoff sheet for all teachers to check and date when they turn in lesson plans. This indicates to all teachers that lesson plans are necessary and important to the daily operation of the school.

This response meets the basic criterion of the structural frame by holding people accountable for their responsibilities and emphasizing productivity and rules. The 
principal's action has a twofold benefit: it addresses the teacher's failure to turn in lesson plans, and it provides a method of record keeping for all teachers.

Human Resource Frame: The principal meets with the teacher individually and compliments him on the quality of his classroom instruction and management. During their conversation, the principal refers to the missing lesson plans and asks if the teacher might suggest any improvements to expedite submitting his lesson plans.

The principal's response exemplifies the human resource frame by fostering a caring and trusting work environment. He displays a supportive leadership approach by enlisting and valuing the teacher's input in improving and correcting the situation.

Political Frame: The principal meets with the teacher and expresses the need for timely lesson plans. He points out that this provides documentation to comply with any monitoring that might take place. He also mentions that students, as stakeholders, could lose valuable instruction during the teacher's absence if no lesson plans are available for a substitute teacher. The principal offers mentoring from another teacher, if needed, for lesson plan writing.

In this response, the principal recognizes the constituents (teacher, principal, substitute teacher, and students) affected by the teacher's neglected lesson plans. The principal manages conflict by 1) justifying timely lesson plan submission and 2) offering the teacher assistance.

Symbolic Frame: The principal sites the most successful substitute teachers as those with adequate plans for classroom instruction. Continuity of instruction provides a better learning experience for students. Classroom management is easier for those who 
step in with a plan for the day. He adds that the school climate is much better when the students are actively engaged in a classroom where proper planning has taken place.

The principal engages the teacher in a discussion about the benefits of appropriate lesson planning and how it impacts the school when it does not occur. He expresses the school's belief in having students actively engaged in a positive learning environment.

Scenario II - The principal implements the team concept in a middle school.

Structural Frame: The principal presents data and research to outline the successful implementation of the team concept in middle schools. The plan clearly defines 1) roles of team members; 2) structures for planning, conflict resolution, and evaluation; and 3) benefits for students and teachers.

In this response, the principal meets the criterion of the structural frame by presenting facts about the team concept regarding its structure and implementation. This approach further highlights the principal as the social architect - analyzer and designer.

Human Resource: The principal discusses the concerns and frustrations teachers have expressed about the perpetual social and emotional conflicts of middle level students. He outlines how the team concept has proven effective in addressing many of those student problems, thus providing teachers with more time to focus on instruction.

The principal identifies concerns expressed by teachers and how the team concept approach would satisfy many of those issues. The response indicates a concern for improving the morale of teachers by addressing their concerns.

Political Frame: Teachers emphasize their need for additional time daily to meet the demands of personal and team planning. The principal facilitates additional planning time in the school's schedule for teachers to plan together daily as a team. 
The principal addresses the competing interests of implementing the team concept in the school and the teachers' concern for not having appropriate time to plan individually and as a team. In his response, the principal focuses on the power relationships within the school (teachers and administration) and how to negotiate the valuable human resource - time.

Symbolic Frame: At the next faculty meeting, the principal spends a few minutes revisiting the school's vision and mission statements. The theme is clear in both statements that this school's faculty is committed to working in concert with one another to provide the best educational opportunities possible for all students. He concludes his remarks in a persuasive and inspiring manner by reminding teachers of their value and importance in fulfilling the commitment of working together as a team for the success of all students. Afterwards, the principal provides every teacher with a poster for classroom display outlining the school's commitment: TEAM - Working Together for the Success of All Students.

In this response, the principal focuses on the meanings and values that reinforce the school's existence - students' success. The poster represented a symbol cultivating commitment, hope, and loyalty within the school.

\section{Studies Regarding Bolman and Deal's Four Frame Model}

Much of the research on Bolman and Deal's four-frame model has centered on determining if the use of multiple frames actually helps leaders in analyzing issues and formulating responses to them. Also, research has been done to determine how the frames are incorporated into the organization's day-to-day life. 
In a study utilizing Bolman and Deal's four frame leadership orientation model (structural, human resources, political, and symbolic) as adapted by Birnbaum (1988) (bureaucratic, collegial, political, and symbolic), Bensimon (1987) examined the degree to which 32 college presidents espoused single or multiple frames in describing and defining good leadership. The extent to which college presidents use single or multiple frames in leadership generally depends on the level of understanding they possess about the breadth, depth, and interconnectedness of the organization. In this study, the preferred frames of college presidents describing good leadership were believed to be reflections of their own leadership behaviors and the expectations they held for themselves.

Analysis of the data from this study identified thirteen college presidents as single-framed (41\%) and eleven as dual-framed (34\%), yielding a total of $75 \%$ of the college presidents being single or dual framed (Bensimon, 1987). Based on Bolman and Deal's (1984) description of leaders using single or dual frames (as noted in Bensimon, 1987), the majority of the college presidents in this study would probably face difficulty if the equilibrium (changes in climate or competition) of the organization were unstable. Data analysis from this study further revealed seven presidents were multi-framed (22\%) and one utilized all four frames (3\%).

In another study of 32 college presidents, Bensimon (1990) expanded data collection beyond presidents' self perceptions of their leadership to include campus leaders' perceptions of the presidents' leadership. The study sought to determine the degree of alignment between the presidents' (self) perceptions and the campus leaders' (other) perceptions. 
Analysis of one component of this study, the degree of alignment of self and others perceptions, indicated that presidents who perceived themselves as being either bureaucratic or non-bureaucratic have communicated this persona to others effectively (agreement of self and others perceptions $-79 \%$ ). On the contrary, those presidents who perceive themselves as exhibiting collegial orientation (60\% agreement) and symbolic orientation (58\% agreement) are not communicating those images to others as clearly (Bensimon, 1990).

Close alignment between the presidents' self perceptions and the perceptions of their followers enhances the potential for successful working relationships. It is important for leaders to understand how their leadership orientation(s) are perceived by others in order to effectively attain intended outcomes. Bensimon (1990) concluded, "the results of this study suggest that awareness of alternative ways of administering may go a long way toward increasing presidents' understanding of how their behaviors may induce or inhibit support for their work" (p. 87).

Bista and Glasman (1998) summarized Bista's (1994) study of administrators' use or perceived use of Bolman and Deal's four leadership frames when employing the nine corresponding management functions (planning, decision-making, reorganizing, evaluating, managing conflict, goal setting, communication, organizing meetings, and motivating). The study hypothesized that the human resource frame would be the dominant leadership orientation of the leaders being studied.

Results from Bista's study supported the hypothesis - the human resource frame was the dominant leadership orientation. In seven of the nine functions, the human resource frame had the highest mean score and the second highest mean score in the 
remaining two functions (organizing meetings and managing conflict). Data from the study further yielded a preference ranking of leadership orientations with mean scores as follows: human resource 3.907, symbolic 3.580, structural 3.563, and political 2.470 . Based on this, it appears that a significant difference exists between the human resource orientation and the political orientation (Bista \& Glasman, 1998).

Human resource as the dominant leadership orientation of principals in this study indicates a propensity to focus on balancing the needs of the organization with the needs of the individuals in the organization. Further, this human resource preference emphasizes the focus on supporting and growing individuals, building relationships and morale, and involving individuals in the management process. This complements the needs identified for successful $21^{\text {st }}$ century school leadership (Bista \& Glasman, 1998; Bolman \& Deal, 1992; Hallinger, 2003; Leithwood \& Jantzi, 2000; Louis \& Marks, 1998).

\section{Studies of the Four-Frame Model Relative to This Study}

Several doctoral dissertation studies have focused on components of this study principals' frame utilization and the level of student achievement. Findings of those studies are presented in this section.

In a study investigating the differences in patterns of principal's leadership behaviors in one mid-Atlantic state, Fears (2004) surveyed principals, teachers, and support staff to ascertain the degree of utilization of Bolman and Deal's four-frame model by principals. The study looked at differences in principal's leadership styles in 1) high performing schools, 2) low performing, and 3) high performing verses low 
performing. There were 21 schools involved in the study, 10 high performing and 11 low performing.

The study yielded no statistically significant difference in frame utilization between principals in the high performing schools and in the high performing verses low performing schools as measured by teachers, principals, and support staff in those schools Further, the study yielded no statistically significant difference in frame utilization between principals in low performing schools as measured by teachers and principals in those schools. There was a statistically significant difference in frame utilization by principals in low performing schools as measured by support staff members in those schools. The statistically significant difference among principals, teachers, and support staff judgments of principals' frame utilization was in the structural dimension, the human resource dimension, and the symbolic dimension. Fears (2004) concluded that high performing schools tend to make support staff feel part of the team as opposed to a less inclusive tendency of low performing schools.

A study by Fleming (2002) investigated differences in elementary principal leadership behaviors as judged by teachers and principals in Comprehensive School Reform Demonstration (CSRD) and Non-Comprehensive School Reform Demonstration (NCSRD) schools. CSRD schools are "low achieving schools that have voluntarily agreed to adopt a total school reform model in return for a three year federal grant" ( $\mathrm{p}$. 15). The total reform consists of changes in a school's "curriculum and academic standards, school governance, community-school relations, staff development, technology, parent involvement, and services to meet children's needs" (p. 14). NonCSRD schools are schools not participating in the three year federal grant. 
Fleming's study looked at principals' frame utilization as judged by teachers and principals across all subgroups: CSRD, NCSRD, urban and rural. Teacher judgments of principals' frame utilization rated the structural frame as the highest utilized of the four frames followed by the human resource, political, and symbolic frames respectively for both CSRD and NCSRD schools. However, the teachers in the CSRD schools rated their principals' frame utilization in all four frames statistically significantly higher than did the teachers in the NCSRD schools. In regard to teacher judgments of principals' frame utilization in urban and rural CSRD and NCSRD schools, teachers in rural schools rated their principals statistically significantly higher for all four frames than did teachers is urban schools.

A second focus of the Fleming (2002) study dealt with teacher judgments of principals' frame utilization by school and student achievement. A composite index (CI) was "developed to provide an indication of the average performance of students in a school across all six content areas (reading, mathematics, writing, language usage, science and social studies) of the State School Performance Program” (p. 15). A final CI was determined by subtracting the 1997 CI from the 2000 CI for each school. In regard to $\mathrm{CI}$ (student achievement), teachers rated the structural frame as the highest utilized of the four frames followed by the human resource, political, and symbolic frames respectively for both CSRD and NCSRD schools. Teachers rated principals' frame utilization in the same pattern, highest to lowest, structural, human resource, political, and symbolic when comparing urban and rural schools.

The study further considered principals' frame utilization across all the subgroups (CRSD, NCRSD, urban and rural) relative to the following demographic variables: 
gender and years in present position. The data show no statistically significant differences in regard to gender in all four areas of principals' frame utilization in urban and rural CSRD schools. However, in the urban and rural NCSRD schools, there were statistically significant differences in principals' frame utilization for all four frames in regard to gender - females had significantly higher mean scores than males.

A couple of interesting side notes from this study: (1) three-fourths of schools identified in the study as improving rated the structural frame as the principal's highest utilized frame; and (2) principals consistently rated themselves higher than their teachers rated them across all four frames.

In a study of 42 Florida elementary and secondary school principals, Poniatowski (2006) sought to determine if there was a relationship between the self-reported leadership orientations of principals and student achievement in reading. The study found no relationship between elementary and secondary principals' frame utilization and students' reading achievement as measured by the Florida Comprehensive Assessment Test (FCAT). In regard to frame utilization, data indicated the human resource frame was the most widely used, and multi-framing occurred regularly. However, the findings of the study indicated that student achievement could possibly be enhanced by providing training for principals in the political and symbolic frames, thus preparing them with leadership skills for the constantly changing school environment.

Ulrich (2004) studied leadership practices of 13 California high school principals whose schools were identified as having sustained high student academic growth for three consecutive years, 2000-2002. The study focused on the use of Bolman and Deal's four leadership frames by high performing high school principals as perceived by 
stakeholders. Principals, assistant principals, department heads, superintendents, and assistant superintendents were surveyed in the study.

Results of the surveys indicated that principals in those high performing schools were identified with the structural and human resource frames in their leadership practices. Ulrich (2004) noted that this was contrary to Bista and Glassman's (1998) findings indicating the human resource frame as the dominant frame for principals. Further, Ulrich found that principals were perceived to use the management functions of communication, decision making, and planning most often.

Follow up interviews were conducted with 10 of the 13 principals considered in Ulrich's study. Results of the interviews indicated that principals perceived themselves as using the human resource frame.

Developing a profile of elementary principals' frame usage was the goal of a study done by Messer (2002). Data were collected from 431 principals in a 15 county region of Florida public schools. The Leadership Orientation (Self) instrument was used in collecting data for this study. The study took into consideration the following demographics: school size, student socioeconomic status, parent volunteer hours, PTA participation, and principal's years of experience.

The study yielded the following significant results: the human resource frame was the most widely used frame, the structural was next, and the political and symbolic frames were the least used by principals. Sixty percent of the principals indicated they used multiple frames in their leadership. The political frame was utilized more frequently by principals in schools having Parent Teacher Association (PTA) membership of $75 \%$ or greater. Additional significant outcomes of this study revealed that principals with 8-11 
years of experience multi-framed more frequently than principals 0-3 years experience, and principals with 0-3 years of experience used the structural frame more frequently than did principals with $12-15$ years of experience. .

Kniewel (1999) sought to explore the differences between teachers' perceptions of their participation in decision making according to the principals' leadership orientation. Survey instruments used in this study were: the Leadership Orientation (Self) instrument for principals and the Teacher Involvement and Participation Scale (Version 2) instrument for teachers.

The results of the Kniewel (1999) study showed that teachers in schools with principals ranking highest in the symbolic frame were more involved in decision-making. Teachers were least involved in schools where the principal ranked highest in the political frame. The symbolic frame emphasizes the importance of shared vision and team building, leadership practices necessary for school renewal and reform. According to Bolman and Deal (2003), the symbolic frame enhances organizational decision-making through rituals that confirm values and create opportunities for bonding (p. 306).

According to Kniewel (1999), the results of this study provide important information about principal leadership behaviors and teacher participation behaviors. Having an understanding of the relationship between leadership and its effect on teacher participation is valuable knowledge for school leaders in this $21^{\text {st }}$ century era of vastly complex problems and issues.

Lewis-Stankus (2007) did a study on the impact of principal leadership behavior in the Smaller Learning Communities on student achievement. The study utilized Bolman and Deal's Leadership Orientation (Other) survey instrument to elicit teacher 
perceptions of principals' leadership styles. The process involved collecting survey data from 456 teachers in 79 schools with smaller learning communities throughout the United States.

The first focus of the study was to ascertain the leadership styles of principals in those 79 schools as perceived by teachers and as measured by the four frames. Results indicated that principals in smaller learning communities utilized the four leadership frames to a similar degree as perceived by teachers (Lewis-Stankus, 2007). The mean for each of the structural, human resource, and political frames was 3.8, and the mean for the symbolic frame was 3.7.

The study also looked at the frequency distribution of principals' leadership by frame patterns: no-frame, single-frame, paired-frame, and multi-frame. The data indicated the following; no-frame $-48.5 \%$, single-frame $-11.1 \%$, paired-frame $-9.0 \%$, and multi-frame $-31.4 \%$.

Lewis-Stankus (2007) further considered the frequency distribution of principals' leadership by frame patterns in regard to the demographic variables of urban and rural, gender, and years of experience. The frequency distribution for urban principals from highest to lowest was: no-frame, multi-frame, paired-frame, and single-frame; and for rural schools was: no-frame, multi-frame, single-frame, and paired-frame. In regard to gender the distribution from highest to lowest was: males - no-frame, paired-frame, multi-frame, and single-frame; and for females - no-frame and multi-frame (tied), and single-frame and paired-frame (tied). Small, medium, and large school size frequency distributions were as follows: small - no-frame, multi-frame, paired-frame, and singleframe; medium - no-frame, multi-frame, single-frame, and paired-frame; and large - no- 
frame, multi-frame, single-frame, and paired-frame. Years of experience distributions from highest to lowest were: 0-5 years - multi-frame, no-frame, single-frame, and pairedframe; 6-10 years - no-frame, multi-frame, paired-frame, and single-frame; and 11 years or more - no-frame, multi-frame, paired-frame, and single-frame.

One other focus of this study looked at the frequency distribution of leadership frame patterns and student achievement in the subject areas of English, Algebra, Social Studies, and Science. The correlation of leadership styles and student achievement indicated the following: English (-.0029), Algebra (.1569), Social Studies (.0767), and Science (.1113). Based on these figures, Lewis-Stankus (2007) concluded that there were no significant differences in student achievement as a result of principals' leadership behavior in schools with Smaller Learning Communities.

\section{Principals' Leadership and Student Achievement}

This section focuses on literature relative to the impact of principals' leadership on student achievement. Further, it looks at some current initiatives aimed at improving the quality of principal leadership and enhancing student achievement. Areas of focus include: reports and legislation impacting principal leadership and student achievement, the Effective Schools Movement, and studies of principals' leadership and student achievement.

\section{Reports and Legislation Impacting Principal Leadership and Student Achievement}

Since the mid 1960s, two nationally known reports and one piece of federal legislation have greatly impacted the leadership role of principals and how that role relates to student achievement. They are: the Coleman Report (1966), A Nation At Risk (1983), and the No Child Left Behind Act of 2001. 
James Coleman (1966) authored the report, On Equality of Educational Opportunity, which determined that schools made little if any impact on student achievement in schools. This revelation prompted vigorous reactions spawning many studies that now serve as the research base for the Effective Schools Movement (Lezotte, 2008b).

The National Commission on Excellence in Education (1983) study entitled, $A$ Nation at Risk, identified deficiencies in schools and pressed for reform efforts to assure quality and equity of educational programs for students - quality in regard to raising levels of student achievement and equity in regard to raising mean-levels of student achievement among various subgroups of students.

The No Child Left Behind Act of 2001 emphasized standards for student learning and accountability measures for schools and districts. The goal of this legislation was to have all students proficient in reading, mathematics, and science by the year 2014 and close the achievement gap between subgroups of students within the school. The principal as instructional leader plays a key role in developing comprehensive educational plans to educate all students in the school, and the principal, in conjunction with teachers, must identify and utilize research-based best instructional practices that yield high levels of student achievement.

\section{The Effective Schools Movement - Instructional Leadership}

The Effective Schools Movement is an outgrowth of the Coleman Report (1966) mentioned earlier. The research of Ron Edmonds and others in the Effective Schools Movement sought to confirm that schools can and do impact student achievement, in spite of students' family backgrounds and their levels of socio-economic status. 
Researchers identified components or correlates found in schools having a positive impact on student achievement for all students. The correlates are: a clear vision and mission; the principal as a strong instructional leader; high expectations for all students; a safe, orderly, and positive environment; a focus on academic achievement and time-on-task; and frequent monitoring practices (Edmonds, 1979).

A major correlate of the Effective Schools Movement (strong instructional leadership) views the principal as being the educational expert in the school. As the expert, the principal's role focuses on standardizing effective teaching practices, maintaining high expectations for students and teachers, supervising curriculum and instruction, and monitoring students' academic progress (Barth, 1986 - as cited in Marks \& Printy, 2003, p. 372). However, at the outset of this movement, principals were without benefit of mentors and coaches to guide them in developing skills necessary to meet the complexities of the role of strong instructional leader. Therefore, instructional leadership fell short in meeting the expectations of improving the quality of instruction and improving student achievement (Cuban, 1984 - as cited in Marks \& Printy, 2003, p. $372)$.

Lezotte (1994) identified some common fallacies with this concept of instructional leadership. One fallacy has to do with the belief that strong instructional leadership implies one person (the principal) 'running the show,' a top-down only type of leadership. A second fallacy deals with the misconception that when subordinates accept the leader's vision, they must replace their professional freedoms with that vision. Sharing a vision is about empowering others. Empowering others is not contrary to the concept of instructional leadership. It is a "logical dispersion of the vision" (p. 4). "It 
recognizes that a principal cannot be the only leader in a complex organization like a school ... and the role of the principal will be changed to that of 'a leader of leaders"' (Lezotte, 2008a, p. 3).

According to Lezotte $(1994,2008 b)$ the instructional leadership correlate is the most controversial of the correlates. The primary reason for the controversy is misinformation about the correlate and its intent, as well as reluctance to allow the principal to serve as a strong instructional leader. If the principal is perceived as a strong instructional leader, this could challenge the status quo and force the school to initiate changes.

Changing $20^{\text {th }}$ century school cultures to fruitful $21^{\text {st }}$ century learning environments will be a difficult chore at the very least. Reforming a school for any reason requires changing the people, the methods, and the culture. Change is not a comfortable thing - generally painful. Usually it creates anxiety and insecurity, and most adults find it difficult to change. For the school leader, it is even more difficult, particularly if change is initiated while past practices and conditions are still in play (Lezotte, 1994).

Lezotte (1994) indicates that there are few effective schools and few strong instructional leaders in the position of principal. Reasons cited for this problem are: principals are trained to be managers, not visionaries, and in most cases principals are recommended for positions based upon their recognized skills as efficient managers.

As researchers have identified schools experiencing total success with students mastering the curricular content, they found these schools to be the 'exception rather than the rule.' Further, they found the source of their success was attributable to the 
intervention of some powerful force - generally the school principal. When these successful schools were further scrutinized, the principal was found to be committed to providing learning for all students, and sharing this commitment with others. The principal was further committed to making this vision a reality through successfully communicating and creating support among those involved in its implementation (Lezotte, 1994; Lezotte \& Pepperl, 1999).

In the midst of the $21^{\text {st }}$ century challenges facing education, there is nothing more powerful than the demand that schools guarantee learning for all. "It is morally correct; today's demographics demand that we find success where before it was optional" (Lezotte, 1994, p. 6). Fullan (2003) maintains that public schools are the main institutions fostering social cohesion in our increasingly diverse society. Therefore, public schools have a moral obligation to serve all children, not just those with loud or powerful advocates. "This means addressing the cognitive and social needs of all children, with an emphasis on including those who may not have been well served in the past" (Fullan, 2003, p. 3).

\section{Studies of Principals' Leadership and Student Achievement}

Andrews and Soder (1987) presented findings from a two year study of Seattle elementary schools which focused on the relationship between principal leadership and student academic achievement. Teachers' perceptions of principals' leadership were measured through an Effective Schools questionnaire concerning nine leadership characteristics. Eighteen questions measuring instructional leadership of the principal focused on four components of the principal's role: resource provider, instructional resource, communicator, and having a visible presence. 
The researchers used gains in reading and mathematics scores disaggregated by subgroups of all students, ethnicity, and free-lunch status to ascertain each school's academic performance. Thirty-three elementary schools provided sufficient achievement data to allow for reliable and valid conclusions. The teacher questionnaires provided data from which the researchers were able to divide the schools into three groups: highest scoring principals - strong leader $(\mathrm{n}=11)$, middle scoring principals - average leader $(\mathrm{n}=11)$, and lowest scoring principals - weak leader $(\mathrm{n}=11)$ (Andrews \& Soder, 1987).

Results of the study indicated that achievement gains for students in strong leader schools were significantly greater in both reading and mathematics than students in the average leader and weak leader schools. The study concluded that "the principal plays a crucial role in the academic performance of students, particularly low-achievers" (Andrews \& Soder, 1987, p. 9). Additionally, the researchers concluded that "where teachers have very positive perceptions of the quality of their workplace, they are more productive, so we see incremental growth in student achievement" (Brandt, 1987, p. 11). Therefore, principal leadership is a key variable in improving student achievement.

Bulach, Lunenburg, and McCallon (1994) conducted a study on the influence of the principal's leadership style on school climate and student achievement in 20 elementary schools in Kentucky. The school sampling represented diverse populations (urban, suburban, and rural) and socio-economic levels. The sampling included third and fifth grade students $(\mathrm{N}=2,834)$, teachers $(\mathrm{N}=506)$, and principals $(\mathrm{N}=20)$. The instrument measuring principals' leadership styles, the Leadership Behavioral Matrix (LBM), measured four behavioral styles: promoters (actively involved with people), 
supporters (heavy on interpersonal relationships), controllers (expect results - their way), and analyzers (problem solvers - data driven) (Bulach, Lunenburg, \& McCallon, 1994).

In regard to the effects of principals' leadership on student achievement, no statistically significant differences were found as a result of this study. The study did determine that the highest achievement scores were in schools of principals exhibiting the promoter (actively involved with people) and analyzer (problem solver - data driven) leadership styles (Bulach, Lunenburg, \& McCallon, 1994).

In addition, this study sought to determine if there was a significant difference in student achievement based on the principal profiles (people verses task/introvert verses extrovert). Again, no statistical difference was found. Those principals deemed "people" oriented $(n=11)$ had a student achievement mean score of 59.78 , while principals identified as "task" oriented $(n=5)$ had a student achievement mean score of 60.36. In regard to extrovert $(n=12)$ and introvert $(n=5)$, student achievement mean scores were 59.43 and 61.50 respectively. Therefore, this study found no significant statistical difference in student achievement resulting from the principals' leadership style (Bulach, Lunenburg, \& McCallon, 1994).

Hallinger, Bickman, and Davis (1990) presented findings of a three year study of 87 Tennessee elementary schools that focused on whether or not principals make a difference in school context and student achievement. The rationale for this study stemmed from the strong belief among practitioners and policymakers that "principals have a discernable impact on the lives of teachers and students" (p.7).

During the first and third year of this study 87 principals completed surveys that focused on specific areas such as: assessment of effective schools factors; organizational 
variables associated with student achievement; faculty attitudes regarding student achievement; personnel incentives; and faculty effectiveness variables. A main focus of this research looked at the consequences of the principal's leadership on the school's instructional program (Hallinger, Bickman, \& Davis, 1990).

The first year assessment model found no direct effect of principal leadership on student achievement. However, the third year assessment model revealed somewhat different results and implications for principal leadership effects on student achievement. The third year model showed a statistically significant positive relationship $(\mathrm{p}<.01)$ between the principal's leadership and school climate variables. The study postulates that climate variables positively impact student achievement in reading $(\mathrm{p}<.05)$. This indicates that principals perceived as strong instructional leaders by their teachers have a greater impact on molding the "school-wide" learning culture and in turn affect student achievement (Hallinger, Bickman, \& Davis, 1990).

\section{$21^{\text {st }}$ Century Initiatives for Improving Principals' Leadership}

Research presented in the previous section highlighted the influence principals' leadership has on student achievement. While the influence appears largely indirect, it warrants cultivation and expansion as schools face the challenges of meeting $21^{\text {st }}$ century student achievement demands. Therefore, the following initiatives addressing those demands are presented in this section: the Institute for Educational Leadership Initiative, and the Southern Regional Educational Board's initiatives. West Virginia is one of 13 states affiliated with the Southern Educational Regional Board. 


\section{School Leadership for the $21^{\text {st }}$ Century Initiative}

The Institute for Educational Leadership (2000) (IEL) is a non-profit, nonpartisan organization that assists agencies and institutions in improving educational opportunities for all children - learning for all. IEL's School Leadership for the $21^{\text {st }}$ Century Initiative, a project undertaken with partnering groups (education, government, business, civic groups, and other organizations involved in educational matters), sought to increase public awareness regarding critical educational leadership issues and call-to-action measures to improve them and thus improve the nation's schools.

The IEL (2000) report identifies several crisis issues facing schools in America today: dilapidated facilities, violence, inadequate staffing, and poor student academic performance. However, perhaps the most critical issue reported was the scarcity of "capable" educational leaders. The report goes on to indicate that this shortage is rapidly growing.

Members of the IEL task force examining the role of the principal and effective school leadership agreed on the following conclusions.

First, the top priority of the principalship must be leadership for learning. Second, the principalship as it currently is constructed - a middle management position over-loaded with responsibilities for basic building operation - fails to meet this fundamental priority, instead allowing schools to drift without any clear vision of leadership for learning or providing principals with the skills needed to meet the challenge. (IEL, 2000, p. 1)

They further agreed that the principalship must be reinvented to meet the demands for $21^{\text {st }}$ century learning. 
The role of the principal is perceived by many, both inside and outside education, to be mainly a managerial function rather than a leadership function. In the past, being a building manager was the standard for effective principal leadership - maintaining a clean and safe facility, managing finances, handling public relations, ordering supplies, and monitoring transportation and food services. While these managerial functions are essential, they do not directly impact the essence of the school's purpose, student learning and achievement. The $21^{\text {st }}$ century principal is faced with administering a school "in an era of rising expectations, complex student needs, enhanced accountability, expanding diversity, record enrollments, and staff shortfalls" (IEL, 2000, p. 3). The report depicts the following instructional leadership responsibilities the $21^{\text {st }}$ century principal must assume:

They must know academic content and pedagogical techniques. They must work with teachers to strengthen skills. They must collect, analyze and use data in ways that fuel excellence. They must rally students, teachers, parents, local health and social service agencies, youth development groups, local businesses, and other community residents and partners around the common goal of raising student performance. And they must have the leadership skills and knowledge to exercise the autonomy and authority to pursue these strategies. (IEL, 2000, p. 2)

\section{Southern Regional Education Board Initiatives}

The Southern Regional Education Board is a nonprofit, nonpartisan organization that works with state governments and educational systems to advance education and improve social and economic life in those states. It is comprised of 16 states, one of which is West Virginia. 
Two of the many Southern Regional Education Board (SREB) initiatives focus on principals' leadership positively affecting student learning. They are: (1) providing training for effective school leadership; and (2) improving the process of selecting quality principals to lead schools. Both SREB initiatives address the focus of this study, which is the relationship between leadership styles of principals and school performance.

The SREB has developed leadership curriculum modules to train aspiring principal candidates and retrain practicing principals in effective leadership practices for today's $21^{\text {st }}$ century schools. Goal 9 of the SREB's training initiative states that "Every school has leadership that results in improved student performance - and leadership begins with an effective school principal” (SREB, 2002, p. 3).

According to SREB (2002), its leadership goal initiatives focus on the need for skilled principals "who first and foremost are instructional leaders" (p. 20). These instructional leaders (principals) must have "in-depth knowledge of curriculum, instruction and how to improve student achievement" (p. 20). Additionally, the astute principal must seek out, attract, and hire "cream of the crop" staff to effectuate quality learning for students.

This SREB initiative has been addressed to some degree in West Virginia State Code $§ 18 \mathrm{~A}-3-2 \mathrm{c}$. This section of code requires the state board of education to promulgate rules regarding the minimum qualities, proficiencies and skills required of principals. In regard to educational proficiencies, the state board of education is required to address rules requiring principals to have knowledge of curriculum, instructional techniques, student learning styles, and student assessment criteria. It further requires that training and professional development programs be provided by the principals' 
academy to build qualities, proficiencies and skills required of all principals as determined by the state board of education.

Additionally, concerning this first initiative of training, the SREB (2002)

maintains that radical changes are needed in leadership preparation programs at colleges and universities. Those programs must be revamped to focus on effective leadership not administrative management. Fulfilling this would involve shifting training from classroom instruction to practical "hands-on" experiences working with teachers and administrators in schools to improve student achievement.

Local school district leaders have major responsibilities in maintaining and perpetuating quality administrators to lead their schools. First, the district must supply programs and trainings that focus on improving student achievement. Second, there must be instructional opportunities about good school leadership models, and a plan for assessing school leadership in schools throughout the district based on those models (SREB, 2002).

The SREB Leadership Curriculum Module (LCM) emphasized the importance of utilizing school teams in effective leadership practices for school principals. An essential for every team member is the willingness to assume responsibility for supervising and improving classroom instruction. SREB's LCM training focuses the school team (principal and teachers) on organizing activities for a learning-centered environment. This, according to the competencies listed under SREB's Critical Success Factors, is predicated on the principal having:

a comprehensive understanding of school and classroom practices that contribute to student achievement. ... the ability to work with teachers and others to design 
and implement continuous student achievement. ... the ability to provide the necessary support for staff to carry out sound school, curriculum and instructional practices. (SREB, 2007, p. 4)

The second SREB initiative focuses on improving the process of selecting quality principals to lead schools. Currently, most school districts, for whatever reason, select principals based on completion of appropriate degree or licensure with little attention given to demonstrated aptitude or skills necessary for the position. This approach, according to the SREB (2007), is flawed and needs to be exchanged for a process to select high performing persons with identified leadership capabilities, who have demonstrated abilities in increasing student achievement and problem solving.

In West Virginia, there are two sections in state code that identify the only licensure or degree requirements mandated for a person to be employed in the position of principal. According to West Virginia State Code §18A-2-9, the prerequisite requirements for issuance of an administrative certificate for principals requires the person to successfully complete at least six hours of approved course work in public school management techniques at an accredited institution of higher education. It further requires the person to have successfully completed education and training in evaluation skills. State Code $§ 18 \mathrm{~A}-3-2$ a states that a professional administrative certificate may be issued to a person who has earned a master's degree in an approved program for administrative certification, completed education and training in evaluation skills, and completed three years of management level experience.

West Virginia State Code $§ 18 \mathrm{~A}-4-7 \mathrm{a}$ indicates that county boards of education are to hire professional personnel other than classroom teachers on the basis of highest 
qualifications. Further, this section of code outlines seven criterion to be considered in hiring a principal. Five of the criterion are objective in nature: certification/licensure, experience, degree level, academic achievement, and previous work evaluations. The remaining two are subjective in nature: consideration of the applicant's relevant specialized trainings, and consideration of other measures on which the applicant may be fairly judged. In these two areas, consideration could focus on trainings and skills of the applicant indicative of effective instructional leadership. Thus, West Virginia State Code $\S 18 \mathrm{~A}-4-7 \mathrm{a}$ is aligned with the SREB initiative aimed at selecting highly qualified principals with demonstrated aptitude or skills necessary for the position.

Prior to considering the two subjective areas (relevant specialized trainings, and consideration of other measures) in the employment process, job requirements would need to be enumerated in the job posting for the principal position. For example, the job posting for a principal position would state the areas of relevant specialized trainings: effective instructional leadership, effective instructional practices, student learning styles, and assessment practices. In addition, the job posting would include other measures to be considered: demonstrated instructional leadership effectiveness and demonstrated focus on student achievement.

West Virginia's alignment with this SREB initiative to select highly qualified principals with demonstrated aptitude or skills is further demonstrated in West Virginia state code $\S 18 \mathrm{~A}-3-2 \mathrm{c}$. As discussed earlier, this section of code requires the state board of education to develop rules outlining the minimum qualities, proficiencies, and skills required of principals. Those minimum qualities, proficiencies, and skills correspond to 
Bolman and Deal's four frame leadership model (structural, human resource, political, and symbolic) as follows:

- staff relations - skills necessary to: utilize faculty senates in a positive manner, lead faculty and staff with courteous and mutual respect, guide and motivate employees, and build consensus. These skills are related to Bolman and Deal's human resource frame - people, caring, and mutual respect; and political frame consensus building (Bolman \& Deal, 1991, 1992, 2003).

- school community leadership qualities - skills necessary to leverage community support, work well with school improvement councils, communicate effectively, lead change, resolve conflict, and demonstrate high values. These skills are related to Bolman and Deal's political frame - leverage support, work with improvement councils, and resolve conflict; and symbolic frame - values (Bolman \& Deal, 1991, 1992, 2003).

- administrative skills - management skills and techniques, organization, fiscal management, and policy. These skills are related to Bolman and Deal's structural frame - policy, rules, and management (Bolman \& Deal, 1991, 1992, 2003).

\section{Summary}

This chapter began with a focus on literature relative to the study of leadership. The evolution of leadership from the early 1900s to today has moved from identifying characteristics possessed by effective leaders to focusing on identifying leadership behaviors that motivate subordinates through support and intellectual stimulation. Leadership that is supportive and intellectually stimulating allows opportunity for individuals within the organization to self-actualize and grow professionally. 
Functioning at this level of leadership, the leader blends the needs of the organization with the needs of individuals. Bolman and Deal's four-frame leadership model focuses on meeting those needs: structural - organization; human resource - individuals; and political and symbolic - both individuals and the organization.

In reviewing studies of Bolman and Deal's identified leadership orientations relative to principals' leadership and its impact on student achievement, a mixture of conclusions was found. Results range from no significant relationship between frame utilization and student achievement to identified positive benefits on student achievement, primarily in the utilization of the structural and the human resource frames. In particular, principals of schools identified as improving and schools maintaining high academic achievement were associated with either the structural frame or the human resource frame, or both. Schools with a high positive correlation between principals' leadership and shared decision-making with teachers identified the symbolic frame as the key leadership function; and schools with high PTA participation identified the political frame as the highest leadership function of the principal.

Further, this chapter reviewed literature substantiating the importance of the leadership role of principals in creating and sustaining effective schools focused on high levels of student achievement. A clear theme of strong instructional leadership was evidenced in several of the works reviewed, that is, the positive impact produced on student achievement where the principal is perceived by teachers to be a strong leader. Additionally, where the principal as a strong leader focuses on providing quality learning for all students and where that focus is shared with others, student academic performance was found to be enhanced and successful. 
The identification and the segregation of principals' duties as being either managerial or instructional leadership was emphasized in some of the studies reviewed. According to research, managerial principal leadership does not provide positive student learning outcomes. Conversely, principals focusing on instructional leadership understand curricular content, effective pedagogical techniques, and how students learn essentials for enhancing student achievement. Further, studies indicate the principal must be an instructional leader who communicates effectively and creates support for initiatives deemed important to the school's mission of learning for all students.

Schools can no longer operate in the mode of "business as usual," according to literature presented in this chapter. The $21^{\text {st }}$ century accountability demands for improving student achievement make it imperative that principals be leaders who bring change - not mere managers of schools. They must establish job priorities to focus on instructional leadership and overcome barriers (personal and organizational) that hinder fulfilling those responsibilities. For an educational leader to remain largely in the managerial realm is to deny the "moral imperative" to lead. Leaders accept responsibility for teaching and learning and are committed to "leading deep cultural change that mobilizes the passion and commitment of teachers, parents, and others to improve the learning of all students...” (Fullan, 2003, p. 41). 


\section{Chapter Three}

\section{Methods}

Chapter Three discusses the methods used in examining the relationship between principals' leadership styles in high and low performing West Virginia elementary schools. Further, this chapter outlines methods used in examining differences in the leadership styles of those principals based on the following demographic variables: gender, years of administrative experience, school location (urban or rural), and school size (small, medium, or large). This chapter is organized as follows: introduction, research design, population, sampling, instrumentation, procedures, data analysis and collection, confidentiality and anonymity, and summary.

\section{Research Design}

The descriptive or survey research design was utilized in this study. This design seeks to determine and describe the way things are. It involves collecting data to test hypotheses or answer questions about the subject being studied. "Typical descriptive studies are concerned with assessing attitudes, opinions, preferences, demographics, practices, and procedures. Descriptive data are usually collected by questionnaire surveys, telephone surveys, interviews, or observations" (Gay, Mills, \& Airasian, 2006, p. 159).

This is a school survey which, according to Gay, Mills, and Airasian (2006), is generally prompted by a need for certain kinds of school related information and "can provide necessary and valuable information to both the schools studied and to other agencies and groups whose operations are school related" (p. 161). In addition, the crosssectional survey format was utilized in this study to gather data. The cross-sectional 
format collects data from selected individuals in a single period of time (Gay, Mills, \& Airasian, 2006).

This study sought to describe the way things are in regard to principals' leadership styles in high and low performing West Virginia elementary schools. It is a School Survey prompted by a need for data to enhance understanding of the landscape of principals' leadership styles in West Virginia. Data for this study was collected through a cross-sectional survey of selected individuals (teachers in identified high and low performing West Virginia elementary schools) in a single period of time.

\section{Population and Sample}

High and low performing public elementary schools in the state of West Virginia provided the sampling population for this study. For the purpose of determining adequate yearly progress (AYP), West Virginia State Board of Education Policy 2320, Section 4.2, defines elementary schools in West Virginia as schools containing any grade configuration of grades K-7, but not grade 8 . There are 395 elementary schools in West Virginia meeting this definition. Sixty of those schools were identified for this study, 30 high performing and 30 low performing.

High and low performing schools were determined based on the most current (2007-2008) West Virginia WESTEST results of students' academic performance in reading and mathematics in the All Students subgroup. A reading mathematics index (RMI) was developed by combining the percents of students making adequate yearly progress (AYP) in both areas for each elementary school in West Virginia. For example, if $90 \%$ of students tested in School A made AYP in reading and $90 \%$ of the students made AYP in mathematics, combining those percents produced a $180 \mathrm{RMI}$ for School A. 
The potential RMI range for schools was from zero to 200. After determining the RMI for each elementary school in West Virginia, schools were rank ordered from lowest to highest - RMI scores ranged from 98.4 to 198.

It was determined that the 30 highest performing and 30 lowest performing schools would be considered for this study which accounts for approximately $15 \%$ of all elementary schools in West Virginia. The high performing schools' RMI range was 183.6-198 and the low performing schools' RMI range was 98.4-135.7. The 47.9-point RMI span between 135.7 and 183.6 establishes a clear margin of distinction between high and low performing schools surveyed in this study.

\section{Instrumentation}

All teachers in the 60 elementary schools identified as the population for this study and the principals of those schools were provided opportunity to participate in the survey process. The total number of teachers in all 60 schools was 1,113 with 446 teachers in the high performing schools and 667 teachers in the low performing schools. Surveys were done electronically through Zoomerang, a widely used commercial grade surveying software product. The web address for Zoomerang is: http://zoomerang.com. Each school was assigned an individual Zoomerang address for the principal's survey and the teachers' survey.

Principals were asked to complete the Principal Questionnaire (Appendix A) which provided demographic data about themselves (gender, and years of experience), and about the school (location of the school (urban or rural), and school size (small, medium, and large). Principals were asked to distribute letters to all teachers in their respective schools requesting their participation in completing the Bolman and Deal 
Leadership Orientation (Other) survey (Appendix B). This survey ascertains their judgments of the principal's leadership style (Bolman, 1990). Surveys were administered to principals and teachers from October, 2008 through January, 2009.

\section{Bolman and Deal's Leadership Orientations (Other) Survey}

Bolman and Deal developed the four leadership frames (structural, human resources, political, and symbolic) during the late 1970s and early 1980s. As a follow-up, during the 1980s they devised the Leadership Orientations instruments to ascertain individuals' inclinations to lead based on each of the four frames. The Leadership Orientations surveys are in two forms, Self and Other. The Self survey is for individuals to rate themselves, and the Other survey is for ratings by colleagues. Lee Bolman granted permission for the use of the Bolman and Deal Leadership Orientations surveys (Appendix C) and permission to administer the survey electronically using Zoomerang software (Appendix D).

Section I of the Leadership Orientations (Other) was utilized in this study. According to Bolman (1990), Section I of the Leadership Orientations (Other) is primarily used for research applications while Sections II and III are used for management development. Section I is a 32 item survey containing eight assessment indicators for each of the four frames (structural, human resources, political, and symbolic). The four frames are in a consistent pattern throughout the survey, that is, structural indicators $(1,5,9,13,17,21,25$, and 29); human resources indicators $(2,6,10$, $14,18,22,26$, and 30); political indicators $(3,7,11,15,19,23,27$, and 31); and symbolic indicators $(4,8,12,16,20,24,28$, and 32). A five-point Likert scale was used to assess the degree to which the evaluator believes the indicator is exhibited by the 
leader (1-Never, 2-Occasionally, 3-Sometimes, 4-Often, and 5-Always). A mean score of 4.0 or better for any one of the four frames indicates the leader's use of that frame in their leadership capacity.

According to Bolman and Deal (1991), there have been no published validity studies done on the Leadership Orientations survey forms. However, the instruments have been widely used by healthcare entities, corporations, higher education, and public education (K-12) agencies across the United States.

In regard to the degree of consistency (reliability) for tests and items measuring each of Bolman and Deal's four frames, Table 3.1 gives the coefficient alpha for the eight data (survey) items for each frame, and the number of data cases completed. Gay, Mills, and Airasian (2006) define coefficient alpha as "the general formula for estimating internal consistency based on a determination of how all items on a test relate to all other items and to the total test" (p. 596). They define correlation coefficient as "a decimal number between -1.00 and +1.00 that indicates the degree to which two variables are related" (p. 596). The $r$ values in Table 3.1 indicate a very high degree of consistency for the eight items measuring each frame and a very high degree of consistency between all 32 items on the Leadership Orientation (Other) survey.

Yet, another test, the split-half reliability test which measures the internal consistency of the items testing Bolman and Deal's four frames, divided the test into two equal halves and correlates scores of both halves. This test yielded the following frame results: structural $(r=.875)$; human resource $(r=.867)$; political $(r=.837)$; and symbolic $(r=.882)$. Thus, the reliability (degree of consistency) of the items measuring the four frames is very high. 
Table 3.1

Reliability of Leadership Orientation Scales

\begin{tabular}{lcc}
\hline \multicolumn{1}{c}{ FRAME } & $\begin{array}{c}\text { Coefficient Alpha } \\
\text { (All items) }\end{array}$ & $\begin{array}{c}\text { Number of Data } \\
\text { Cases Completed }\end{array}$ \\
\hline Structural & $\mathrm{r}=.920$ & 1,309 \\
Human Resource & $\mathrm{r}=.931$ & 1,331 \\
Political & $\mathrm{r}=.913$ & 1,268 \\
Symbolic & $\mathrm{r}=.931$ & 1,315 \\
\hline Note. From Bolman, L. (1990). http://www.leebolman.com/orientations.htm. Adapted with permission of \\
\\
the author (Appendix J).
\end{tabular}

\section{Data Collection Procedures}

Principals of the 60 schools identified as the population for this study were mailed informational packets via the US Mail. The packet contained a Principal Participant Letter (Appendix E) and copies of the Teacher Participant Letters (Appendix F) for each teacher on their staff. The Principal Participant Letter and the Teacher Participant Letters explained how participants were to access the survey website, complete their respective surveys, and submit them. In total, this study sought survey responses from a total of 60 principals and 1,113 teachers in 30 high performing and 30 low performing West Virginia elementary schools. The acceptable rate of return for teacher surveys was at least $40 \%$ of the teachers in at least $40 \%$ of both the high and the low performing schools considered in this study, at least 12 schools from each group.

Participants (principals and teachers) were asked to complete the surveys between Monday, October 20, 2008, and Friday, January 23, 2009. At the end of three weeks in the surveying process (November 10, 2008), a follow-up telephone call (Appendix G) was made to schools not responding and schools with a low rate of return to further request their participation. A second follow up telephone call was made to schools not 
responding and incomplete responding schools beginning the week of December 1, 2008, and a third follow-up telephone call was made to schools not responding and incomplete responding schools beginning the week of January 4, 2009.

\section{Data Analysis}

The Bolman and Deal (1990) Leadership Orientations (Other) survey form and the Principal Questionnaire survey form were used to gather data for analysis in this study. The Statistical Package for the Social Sciences (SPSS) software was used to analyze the data. Data regarding teachers' perceptions of principals' leadership styles were analyzed to determine the following: (1) is there a difference in the leadership styles of principals in high and low performing West Virginia elementary schools; (2) do high and low performing elementary principals in West Virginia exhibit multiple leadership frames (structural, human resources, political and symbolic) as opposed to a single frame, or no frame; and (3) are there differences in principals' frame utilization in high and low performing West Virginia elementary schools according to various demographic variables (gender, years of administrative experience, school location (urban or rural, and school size (small, medium, or large). The following research questions and statistical computations yielded data for analysis.

Question 1: Based on teacher perceptions, what are the leadership styles of principals in high and low performing West Virginia elementary schools as measured by the four frames (structural, human resource, political, and symbolic)?

Hypothesis: Based on teacher perceptions, there are statistically significant differences in means of leadership styles of principals in high and low performing West Virginia elementary schools. 
A test comparing the mean and standard deviation for each frame (structural, human resource, political, and symbolic) was used to determine frame utilization of West Virginia elementary principals considered in this study (high and low performing). A descriptive frequency test was used to describe the leadership styles (no-frame, singleframe, paired-frame, and multi-frame) of those principals.

Question 2: Based on teacher perceptions, what are the differences in the number of frames utilized (none, single, paired, and multiple) by principals in high and low performing West Virginia elementary schools?

Hypothesis: Based on teacher perceptions, there are statistically significant differences in means of the number of frames utilized (none, single, paired, and multiple) by principals in high and low performing West Virginia elementary schools.

An independent t-test was used to determine frame utilization differences between principals in high and low performing West Virginia elementary schools. A descriptive frequency test was used to describe the leadership styles (no-frame, single-frame, pairedframe, and multi-frame) of each group (principals in high and low performing schools).

Question 3: Based on teacher perceptions, what are the differences in principals' frame utilization (structural, human resource, political, and symbolic) in high and low performing West Virginia elementary schools according to gender?

Hypothesis: Based on teacher perceptions, there are statistically significant differences in means of principals' frame utilization in high and low performing West Virginia elementary schools according to gender.

An independent t-test was used to determine frame utilization differences between principals in high and low performing West Virginia elementary schools according to 
gender. A descriptive frequency test was used to describe the leadership styles (noframe, single-frame, paired-frame, and multi-frame) of male and female West Virginia elementary principals in high and low performing schools.

Question 4: Based on teacher perceptions, what are the differences in principals' frame utilization (structural, human resource, political, and symbolic) in high and low performing West Virginia elementary schools according to the number of years of administrative experience $(0-5,6-10$, greater than 10$)$ ?

Hypothesis: Based on teacher perceptions, there are statistically significant differences in means of principals' frame utilization in high and low performing West Virginia elementary schools according to years of administrative experience (0-5, 6-10, greater than 10).

An analysis of variance (ANOVA) test was used to determine frame utilization differences between principals in high and low performing West Virginia elementary schools according to years of administrative experience. A descriptive frequency analysis was used to describe the leadership styles (no-frame, single-frame, paired-frame, and multi-frame) of West Virginia elementary principals in high and low performing schools with 0-5, 6-10, and greater than 10 years of administrative experience.

Question 5: Based on teacher perceptions, what are the differences in principals' frame utilization (structural, human resource, political, and symbolic) in high and low performing West Virginia elementary schools according to school location (urban or rural)? 
Hypothesis: Based on teacher perceptions, there are statistically significant differences in means of principals' frame utilization in high and low performing West Virginia elementary schools according to school location (urban or rural).

An independent t-test was used to determine frame utilization differences between principals in high and low performing West Virginia elementary schools according to school location. A descriptive frequency analysis was used to describe the leadership styles (no-frame, single-frame, paired-frame, and multi-frame) of West Virginia elementary principals in high and low performing schools in urban and rural locations.

Question 6: Based on teacher perceptions, what are the differences in principals' frame utilization (structural, human resource, political, and symbolic) in high and low performing West Virginia elementary schools according to school size (small, medium, or large)?

Hypothesis: Based on teacher perceptions, there are statistically significant differences in means of principals' frame utilization in high and low performing West Virginia elementary schools according to school size (small, medium, or large).

An independent t-test was used to determine frame utilization differences between principals in high and low performing West Virginia elementary schools according to school size. A descriptive frequency analysis was used to describe the leadership styles (no-frame, single-frame, paired-frame, and multi-frame) of high and low performing West Virginia elementary principals in small, medium, and large size schools.

\section{Anonymity and Confidentiality}

All schools identified as qualifying for this study were assigned an identification number for confidentiality purposes. All participants received a cover letter explaining 
the purpose of the research, the voluntary participation option, the right of not responding to all questions, and the protection of participants' anonymity and confidentiality in accordance with Institutional Review Board guidelines. In regard to anonymity and confidentiality, the letter informed participants that all surveys would be nameless and there would be no tracking of the electronic submissions of responses. Further, the letter indicated that data results filed for each school surveyed would be confidentially maintained and not released. The West Virginia University Institutional Review Board approval for completing this study is presented in Appendix $\mathrm{H}$.

\section{Summary}

Chapter Three addressed the methods used in this study to answer questions germane to principal leadership in high and low performing elementary schools in West Virginia and student achievement in those schools. This chapter defined the research design, the population sampling, the data collection instruments, and how data were collected and analyzed in the study. Finally, the chapter provided assurances of anonymity and confidentiality for participants in the study. 


\section{Chapter Four}

\section{Findings}

Chapter Four presents the results regarding teacher perceptions of the leadership styles of principals in high and low performing West Virginia elementary schools. This study examined whether there is a statistically significant difference in those leadership styles based on the conceptual framework of Bolman and Deal's four frame leadership model (structural, human resource, political, and symbolic). Data detailing teacher perceptions of principal leadership styles were collected and analyzed in the following areas: frame utilization (structural, human resource, political, and symbolic); leadership style (no-frame, single-frame, paired-frame, and multi-frame); gender; years of administrative experience (0-5 years, 6-10 years, and greater than 10 years); school location (urban or rural); and school size (small, medium, and large).

The first section of this chapter outlines the demographic data of principal and teacher respondents. The second section examines the reliability of the survey instrument, Leadership Orientation (Other). The third section focuses on analysis of data for each of the six research questions. The last section summarizes the chapter and the findings of the study.

\section{Respondents}

There were 60 West Virginia elementary schools (30 high performing and 30 low performing) identified for consideration in this study. Therefore, the study included 60 principals as a target sample. It was anticipated that at least $40 \%$ of these principals in both the high and low performing categories would participate in the study; thus, at least 12 principals in each category. In order to participate, the principal had to complete the 
online demographic survey and at least $40 \%$ of the teachers in that school had to complete the online leadership survey

Twenty-one principals in high performing schools and 21 principals in low performing schools responded to the school and personal demographics survey. In total, 247 teachers responded to the leadership survey, of whom 114 teachers were from 22 high performing schools and 133 were from 21 low performing schools. However, only 27 responding principals qualified for leadership evaluation by having the required $40 \%$ teacher responses from their schools. Therefore, the valid principal response rate was 45\%. A total of 196 teachers (88 from high performing schools and 108 from low performing schools) evaluated these 27 principals on their utilization of leadership frames, an average of approximately seven teachers per principal.

Table 4.1 presents survey responses by demographic variables. Among the 27 principals who qualified for this leadership study (based on their demographic information and teachers' evaluation responses), 13 or about $48 \%$ were from high performing schools and 14 or nearly $52 \%$ were from low performing schools. By gender, $37 \%$ of the principals were male and $63 \%$ were female. At the time of this study, $38 \%$ (151) of the principals in West Virginia elementary schools were male and 62\% (244) were female (WVDE, 2009). Among qualifying principals, 10 had five or fewer years of administrative experience; seven had six to 10 years of administrative experience; and 10 had 10 years or greater experience. By school location, a vast majority of the 27 principals were from rural schools, while only 8 or about $30 \%$ were from urban schools. By school size, 15 were from small size schools and 12 were from medium size schools. No large size schools qualified for this study. 
Table 4.1

Survey Responses by Demographic Variables

\begin{tabular}{|c|c|c|c|c|}
\hline \multirow[t]{2}{*}{ Demographic Variable } & \multicolumn{2}{|c|}{ Principals } & \multicolumn{2}{|c|}{ Teacher Raters } \\
\hline & Number & $\%$ & Number & $\%$ \\
\hline \multicolumn{5}{|l|}{ School Performance Category } \\
\hline High & 13 & 48.2 & 88 & 44.9 \\
\hline Low & 14 & 51.8 & 108 & 55.1 \\
\hline \multicolumn{5}{|l|}{ Gender } \\
\hline Male & 10 & 37.0 & 77 & 39.3 \\
\hline Female & 17 & 63.0 & 119 & 60.7 \\
\hline \multicolumn{5}{|l|}{ Administrative Experience } \\
\hline $0-5$ Years & 10 & 37.0 & 70 & 35.7 \\
\hline $6-10$ Years & 7 & 26.0 & 46 & 23.5 \\
\hline Greater Than 10 Years & 10 & 37.0 & 80 & 40.8 \\
\hline \multicolumn{5}{|l|}{ School Location } \\
\hline Urban & 8 & 29.6 & 59 & 30.1 \\
\hline Rural & 19 & 70.4 & 137 & 69.9 \\
\hline \multicolumn{5}{|l|}{ School Size } \\
\hline Small & 15 & 55.6 & 85 & 43.4 \\
\hline Medium & 12 & 44.4 & 111 & 56.6 \\
\hline Total & 27 & & 196 & \\
\hline
\end{tabular}

Reliability of Survey Instrument

Cronbach alpha is a measure of inter-item reliability. Based on all survey data received in this study utilizing the Bolman and Deal Leadership Orientation (Other) survey, the Cronbach alpha analysis was used to determine the inter-item reliability for each of the four frames. The results were as follows: structural .943, human resource .945 , political .948 , and symbolic .951 . In comparison, Bolman (1990) presented Cronbach alphas for research on the four frames: structural .933 , human resource .931 , 
political .913 , and symbolic .931 . Both inter-item reliability tests indicate the survey instrument used to gather data for this study was highly reliable.

\section{Analysis of Data}

This section presents major findings of the data analysis as it pertains to each of the research questions in this study. In regard to significance testing, the .05 level was used for all statistical tests.

Question 1. Based on teacher perceptions, what are the leadership styles of principals in high and low performing West Virginia elementary schools as measured by the four frames (structural, human resource, political, and symbolic)?

Table 4.2 presents the means and standard deviations of teacher perceptions $(n=$ 196) for principals in high and low performing West Virginia elementary schools for the four leadership frames (structural, human resource, political, and symbolic). The human resource frame had the highest mean $(M=4.19, S D=0.82)$, followed by the structural frame $(M=4.14, S D=0.79)$ and the political frame $(M=3.99, S D=0.82)$. The symbolic frame had the lowest mean $(M=3.98, S D=0.87)$.

Table 4.2

Means and Standard Deviations of Principals' Leadership Frames Rated by Teachers

\begin{tabular}{lcc}
\hline \multicolumn{1}{c}{ Leadership Frame } & Mean & Standard Deviation \\
\hline Structural & 4.14 & 0.79 \\
Human Resource & 4.19 & 0.82 \\
Political & 3.99 & 0.82 \\
Symbolic & 3.98 & 0.87 \\
\hline
\end{tabular}

A mean score of 4.0 or better for any one of the four leadership frames indicates usage of that frame. Based on the mean score for each frame in Table 4.2, West Virginia 
elementary principals in high and low performing schools were more likely to use the structural and human resource frames and less likely to use the political and symbolic frames in their leadership.

The teacher participants' ratings of school principals were analyzed according to whether they used one frame (single-frame), two frames (paired-frame), three or four frames (multi-frame), or no-frame. Table 4.3 presents the frequency and percentage of the four categories of principals' leadership frame use as reported by teachers. Teachers rated five principals $(18.5 \%)$ as not consistently using any frames (no-frame leadership style). They indicated that 14.8 percent $(n=4)$ each used a single-frame leadership style; 11.1 percent $(n=3)$ used a paired-frame leadership style; and a majority $(n=15,55.6 \%)$ used a multi-frame leadership style. Principals were more likely to adopt a multi-frame leadership style rather than the single, paired, or no-frame style.

The frequency distribution for frame patterns within each of the three categories (single, paired, and multi) is also presented in Table 4.3. Within the single-frame category, two principals were reported as using the structural frame (50\%). One each was reported as using the human resource and political frame. None of the principals in the single-frame category were perceived by teachers as using the symbolic frame.

Of the three paired-frame principals noted in Table 4.3, teachers rated two as using a combination of the structural and human resource frames, and rated one as using a combination of the structural and political frames. No principal followed the combined patterns of the structural and symbolic frames, the human resource and political frames, the human resource and symbolic frames, or the political and symbolic frames according to teacher perceptions. 
Table 4.3

Frequency Distribution of Principals’ Leadership Style by Frame Pattern

\begin{tabular}{lccc}
\hline \multicolumn{1}{c}{ Category/Pattern } & Frequency & $\begin{array}{c}\% \text { (as to } \\
\text { category) }\end{array}$ & $\begin{array}{c}\% \text { (as to } \\
\text { total) }\end{array}$ \\
\hline No-frame & & 100.0 & 18.5 \\
Single-frame & & & \\
Structural & 2 & 50.0 & 7.4 \\
Human Resource & 1 & 25.0 & 3.7 \\
Political & 1 & 25.0 & 3.7 \\
Sub-Total & 4 & 100.0 & 14.8 \\
Paired-frame & & & \\
Structural/Human Resource & & & 7.4 \\
Structural/Political & 2 & 66.7 & 3.7 \\
Sub-Total & 1 & 33.3 & 11.1 \\
Multi-Frame & 3 & 100.0 & \\
Structural/Human Resource/Political & & & 3.7 \\
Structural/Human Resource/Political/Symbolic & 14 & 93.3 & 51.9 \\
Sub-Total & 15 & 100.0 & 55.6 \\
Total & & & 100.0 \\
\hline
\end{tabular}

For the combined patterns of the multiple leadership frames shown in Table 4.3, almost all of principals were reported as using the four-frame pattern (structural, human resource, political and symbolic). Only one principal was perceived by teachers to adopt the combination of the structural, human resource, and political frames.

As for all patterns (no-frame, single-frame, paired-frame, and multi-frame), teachers reported in Table 4.3 that more than half of the principals followed the combination of the multi-frame (four frames) leadership style most commonly. This was followed by the no-frame and single-frame styles. The paired-frame category was used least. 
The focus of question one was solely to determine the leadership styles of principals in high and low performing West Virginia elementary schools as measured by the four frames. Therefore, no testing was done to determine statistically significant differences in frame utilization (structural, human resource, political, and symbolic) and leadership styles (no-frame, single-frame, paired-frame, and multi-frame).

Question 2. Based on teacher perceptions, what are the differences in the number of frames utilized (no, single, paired, and multiple) by principals in high and low performing West Virginia elementary schools?

Table 4.4 presents the means and standard deviations of principals' utilization of the four leadership frames by school performance type (high and low), as well as the comparative results of a $t$ test. The mean of the utilization of the structural frame by principals from high performing schools reported by teachers was 4.42 with a standard deviation of 0.64 , while the mean of the utilization of this frame by principals from low performing schools was 3.91 with a standard deviation of 0.84 . The $t$ test analysis showed that there was a significant difference in the utilization of the structural frame by principals between high and low performing schools , $t=4.76, p<.001$. According to teacher perceptions, principals in high performing schools were more likely to use the structural frame than principals in low performing schools.

The means of teacher perceptions of the utilization of the human resource frame by principals in high and low performing schools were $4.36(S D=0.78)$ and $4.04(S D=$ 0.82), respectively (Table 4.4). Again, the $t$ test analysis reveals that principals in high performing schools were perceived by teachers to be significantly more likely to use the human resource frame than principals in low performance schools, $t=2.78, p<.01$. 
Table 4.4

Difference in Principals' Utilization of Leadership Frames Reported by Teachers by School Performance Type

\begin{tabular}{lccccc}
\hline \multirow{2}{*}{ Leadership Frame } & \multicolumn{2}{c}{ High $(N=88)$} & \multicolumn{2}{c}{ Low $(N=108)$} & \multirow{2}{*}{$t$} \\
\cline { 2 - 5 } & Mean & SD & Mean & SD & \\
\hline Structural & 4.42 & 0.64 & 3.91 & 0.84 & $4.76 * * *$ \\
Human Resource & 4.36 & 0.78 & 4.04 & 0.82 & $2.78^{* *}$ \\
Political & 4.22 & 0.75 & 3.81 & 0.84 & $3.58 * * *$ \\
Symbolic & 4.13 & 0.87 & 3.86 & 0.86 & $2.23 *$ \\
\hline${ }_{p} p<0.05 ; * * p<0.01 ; * * * p<0.001$ & & & &
\end{tabular}

According to teacher perceptions, principals in high performing schools averaged 4.22 in the use of the political frame and their counterparts in low performing schools averaged 3.81 (Table 4.4). The degree to which they used this frame was significantly different as indicated by a $t$ test, $t=3.58, p<.001$. Thus, principals in high performing schools were more likely to use this frame than principals in low performing schools.

The mean of the utilization of the symbolic frame by principals in high performing schools as evaluated by teachers was 4.13 with a standard deviation of 0.87 , compared to 3.86 with a standard deviation of 0.86 for those in low performing schools (Table 4.4). Thus, principals in high performing schools were more likely to use the symbolic frame than were their counterparts in low performing schools, $t=2.23, p<.05$.

A mean score of 4.0 or better for any one of the four leadership frames indicates usage of that frame. Based on the mean score for each frame (structural, human resource, political, and symbolic) in Table 4.4, West Virginia elementary principals in high performing schools were using all four frames in their leadership; principals in low performing schools were using only the human resource frame. 
Therefore, based on teacher perceptions, the hypothesis "there are statistically significant differences in means of the number of frames utilized by principals in high and low performing West Virginia elementary schools" was accepted for all four frames. Principals in high performing schools were statistically more likely to use all four frames than principals in low performing schools.

Table 4.5 displays frequency distribution of principals' leadership style by school performance type (high and low). A vast majority of principals in high performing schools followed a multi-frame leadership style, accounting for nearly $85 \%$ of all principals evaluated by teachers. Ten of the 11 high performing multi-frame principals Table 4.5

Frequency Distribution of Principals' Leadership Style by School Performance Type

\begin{tabular}{lcccc}
\hline \multicolumn{1}{c}{ Category/Pattern } & \multicolumn{2}{c}{ High } & \multicolumn{2}{c}{ Low } \\
\cline { 2 - 5 } & Frequency & $\%$ & Frequency & $\%$ \\
\hline No-frame & 1 & 7.6 & 4 & 28.6 \\
Single-frame & & & & \\
Structural & 1 & 7.6 & 1 & 7.1 \\
Human Resource & 0 & 0.0 & 1 & 7.1 \\
Political & 0 & 0.0 & 1 & 7.1 \\
Sub-Total & 1 & 7.6 & 3 & 21.3 \\
Paired-frame & & & & \\
Structural/Human Resource & 0 & 0.0 & 2 & 14.3 \\
Structural/Political & 0 & 0.0 & 1 & 7.1 \\
Sub-Total & 0 & 0.0 & 3 & 21.3 \\
Multi-Frame & & & & \\
Structural/HR/ Political & 1 & & & \\
Structural/HR/Political/Symbolic & 10 & 76.9 & 4 & 28.6 \\
Sub-Total & 11 & 84.5 & 4 & 28.6 \\
Total & 13 & 100.0 & 14 & 100.0 \\
\hline
\end{tabular}


used all four frames. The other two principals in high performing schools each used a no-frame style or a single-frame leadership style. For the 14 principals in low performing schools rated by teachers, four each used the no-frame and multi-frame leadership styles, accounting for approximately $29 \%$, respectively, and three each adopted the single-frame and paired-frame styles, accounting for about $21 \%$, respectively. Within each category, principals in low performing schools used the following combinations: multi-frame in combinations of the four frames; paired-frame with two using a combination of the structural and human resource frames, and one using a combination of the structural and political frames; and single-frame with one each using the structural frame, the human resource frame, and the political frame.

Question 3. Based on teacher perceptions, what are the differences in principals' frame utilization (structural, human resource, political, and symbolic) in high and low performing West Virginia elementary schools according to gender?

Table 4.6 presents means and standard deviations of the utilization of leadership frames by principals by gender as reported by teachers. The means of male principals' utilization of the structural, political, and symbolic frames were $4.02(S D=0.84), 3.92$ $(S D=0.86)$, and $3.84(S D=0.87)$, respectively, compared to $4.21(S D=0.74), 4.04(S D$ $=0.80)$, and $4.07(S D=0.86)$ for female principals' utilization of these three frames. The $t$ test analysis indicated there were no statistically significant differences in principals' utilization of these three leadership frames. The mean of male principals' utilization of the human resource frame was 4.01 with a standard deviation of 0.84 and the mean of their female counterparts' use of this frame was 4.30 with a standard deviation of 0.79 . The $t$ test analysis indicates that male principals were significantly less likely to use the 
human resource frame than female principals as perceived by teachers, $t=-2.47, p<$ 0.05 .

Table 4.6

Difference in Principals' Utilization of Leadership Frames Reported by Teachers by Gender

\begin{tabular}{lccccc}
\hline \multirow{2}{*}{ Leadership Frame } & \multicolumn{2}{c}{ Male $(N=77)$} & \multicolumn{2}{c}{ Female $(N=119)$} & \multirow{2}{*}{$t$} \\
\cline { 2 - 5 } & Mean & SD & Mean & SD & \\
\hline Structural & 4.02 & 0.84 & 4.21 & 0.74 & -1.71 \\
Human Resource & 4.01 & 0.84 & 4.30 & 0.79 & $-2.47^{*}$ \\
Political & 3.92 & 0.86 & 4.04 & 0.80 & -0.96 \\
Symbolic & 3.84 & 0.87 & 4.07 & 0.86 & -1.84 \\
\hline${ }^{*} p<0.05$ & & & & &
\end{tabular}

Therefore, based on teacher perceptions, the hypothesis "there are statistically significant differences in means of the number of frames utilized by principals in high and low performing West Virginia elementary schools according to gender" was accepted for the human resource frame. Female principals were statistically more likely to use the human resource frame than male principals.

As presented in Table 4.7, in terms of teacher perceptions, $20 \%$ of male principals included in this study did not consistently use any frames, 30\% used a single-frame leadership style, and half used a multi-frame approach. For female principals, about $18 \%$ did not consistently use any frames, $6 \%$ followed a single-frame approach, $18 \%$ followed a paired-frame style, and nearly $60 \%$ adopted a multi-frame style. Together, approximately $80 \%$ of females either used the paired-frame or the multi-frame leadership approach as compared to only $50 \%$ of males who use the paired-frame or multi-frame leadership approach. Within the single-frame category, one male principal each used the structural, the human resource, and the political frame and only one female principal used 
Table 4.7

Frequency Distribution of Principals’ Leadership Style by Gender

\begin{tabular}{lcccc}
\hline \multicolumn{1}{c}{ Category/Pattern } & \multicolumn{2}{c}{ Male } & \multicolumn{2}{c}{ Female } \\
\cline { 2 - 5 } & Frequency & $\%$ & Frequency & $\%$ \\
\hline No-frame & 2 & 20.0 & 3 & 17.7 \\
Single-frame & & & & \\
$\quad$ Structural & 1 & 10.0 & 1 & 5.9 \\
$\quad$ Human Resource & 1 & 10.0 & 0 & 0.0 \\
Political & 1 & 10.0 & 0 & 0.0 \\
Sub-Total & 3 & 30.0 & 1 & 5.9 \\
Paired-frame & & & & \\
Structural/Human Resource & 0 & 0.0 & 2 & 11.8 \\
Structural/Political & 0 & 0.0 & 1 & 5.9 \\
Sub-Total & 0 & 0.0 & 3 & 17.7 \\
Multi-Frame & & & & \\
Structural/HR/Political & 1 & 10.0 & 0 & 0.0 \\
Structural/HR/Political/Symbolic & 4 & 40.0 & 10 & 58.8 \\
Sub-Total & 5 & 50.0 & 10 & 58.8 \\
$\quad$ Total & 10 & 100.0 & 17 & 100.0 \\
\hline
\end{tabular}

the structural frame. No males or females in the single-frame leadership category evidenced use of the symbolic frame as their leadership approach. Within the pairedframe category, two female principals adopted a combination of the structural and human resource frames and one followed a combination of the structural and political frames. No male principals exhibited the paired-frame leadership approach. Most or all of male and female principals who followed a multi-frame leadership style tended to use all four frames. Only one male principal used a combination of three frames (structural, human resource, and political). 
Question 4. Based on teacher perceptions, what are the differences in principals' frame utilization (structural, human resource, political, and symbolic) in high and low performing West Virginia elementary schools according to the number of years of administrative experience $(0-5,6-10$, greater than 10$)$ ?

Table 4.8 reveals means and standard deviations of teacher perceptions of principal utilization of the four frames by administrative experience. The means for the structural and human resource frames by principals with less than six years of administrative experience were slightly higher than the means for principals with six to 10 or greater than 10 years of administrative experience, while those with greater than 10 years of administrative experience averaged slightly higher on the political and symbolic frames than the other two groups.

Table 4.8

Difference in Principals' Utilization of Leadership Frames Reported by Teachers by Administrative Experience

\begin{tabular}{lccccccc}
\hline \multirow{2}{*}{ Leadership Frame } & \multicolumn{2}{c}{$\begin{array}{c}0-5 \text { Years } \\
(N=70)\end{array}$} & \multicolumn{2}{c}{$\begin{array}{c}\text { 6-10 Years } \\
(N=46)\end{array}$} & \multicolumn{2}{c}{$\begin{array}{c}> \\
(N=80)\end{array}$} & \\
& Mean & SD & Mean & SD & Mean & SD & \\
\cline { 2 - 7 } & 4.18 & 0.75 & 4.09 & 0.89 & 4.13 & 0.78 & 0.18 \\
Structural & 4.26 & 0.68 & 4.00 & 1.06 & 4.23 & 0.76 & 1.66 \\
Human Resource & 4.03 & 0.77 & 3.85 & 1.01 & 4.05 & 0.75 & 0.97 \\
Political & 3.99 & 0.76 & 3.77 & 1.06 & 4.10 & 0.83 & 2.07 \\
Symbolic & & & & & & & \\
\hline
\end{tabular}

The analysis of variance (ANOVA) results, however, showed no statistically significant difference in principals' utilization of any of the four frames based on years of administrative experience. Therefore, based on teacher perceptions, the hypothesis "there are statistically significant differences in means of the number of frames utilized by principals in high and low performing West Virginia elementary schools according to 
years of administrative experience" was rejected for all four frames (structural, human resource, political, and symbolic).

Table 4.9 includes a frequency distribution of principals' leadership style by administrative experience. Among 10 principals with 0-5 years of administrative experience, seven or $70 \%$ followed the multi-frame leadership approach, two used the paired-frame approach, and one used the no-frame leadership approach. For seven principals with 6-10 years of administrative experience, teachers reported that three each followed the no-frame and the multi-frame leadership approaches. One used the singleTable 4.9

Frequency Distribution of Principals' Leadership Style by Administrative Experience

\begin{tabular}{lcccccc}
\hline \multirow{2}{*}{ Category/Pattern } & \multicolumn{2}{c}{$0-5$ Years } & \multicolumn{2}{c}{6 -10 Years } & \multicolumn{2}{c}{ 10 Years } \\
\cline { 2 - 6 } & Frequency & $\%$ & Frequency & $\%$ & Frequency & $\%$ \\
\hline No-frame & 1 & 10.0 & 3 & 42.9 & 1 & 10.0 \\
Single-frame & & & & & & \\
Structural & 0 & 0.0 & 0 & 0.0 & 2 & 20.0 \\
Human Resource & 0 & 0.0 & 1 & 14.3 & 0 & 0.0 \\
Political & 0 & 0.0 & 0 & 0.0 & 1 & 10.0 \\
Sub-Total & 0 & 0.0 & 1 & 14.3 & 3 & 30.0 \\
Paired-frame & & & & & & \\
St/HR & 1 & 10.0 & 0 & 0.0 & 1 & 10.0 \\
Structural/Political & 1 & 10.0 & 0 & 0.0 & 0 & 0.0 \\
Sub-Total & 2 & 20.0 & 0 & 0.0 & 1 & 10.0 \\
Multi-Frame & & & & & & \\
$\quad$ Structural/HR/Political & 1 & 10.0 & 0 & 0.0 & 0 & 0.0 \\
Structural/HR/Political/ & & & & & & \\
$\quad$ Symbolic & 6 & 60.0 & 3 & 42.9 & 5 & 50.0 \\
Sub-Total & 7 & 70.0 & 3 & 42.9 & 5 & 50.0 \\
Total & 10 & 100.0 & 7 & 100.0 & 10 & 100.0 \\
\hline
\end{tabular}


frame leadership style, the human resource frame. Among 10 principals with more than 10 years of administrative experience, half were perceived by teachers to adopt the multiframe leadership approach, three used the single-frame style (two - structural and one political), one did not consistently use any frame, and one used the paired-frame leadership approach (a combination of two frames, the structural and human resource frames).

Question 5. Based on teacher perceptions, what are the differences in principals' frame utilization (structural, human resource, political, and symbolic) in high and low performing West Virginia elementary schools according to school location (urban/rural)?

Table 4.10 presents mean differences in principals' utilization of leadership frames as evaluated by teachers from urban and rural schools. The principals from rural schools averaged higher on all four frames than did the principals from urban schools according to teacher perceptions. The $t$ test analysis did not indicate statistically significant differences in the use of the structural, human resource, and symbolic frames. However, the analysis did show that principals from rural schools are significantly more likely to use the political frame than principals from urban schools.

Table 4.10

Difference in Principals' Utilization of Leadership Frames Reported by Teachers by School Location

\begin{tabular}{lccccc}
\hline Leadership Frame & \multicolumn{2}{c}{ Urban $(\mathrm{N}=59)$} & \multicolumn{2}{c}{ Rural $(\mathrm{N}=137)$} & \multirow{2}{*}{$t$} \\
\cline { 2 - 5 } & Mean & SD & Mean & SD & \\
\hline Structural & 4.00 & 0.96 & 4.08 & 0.71 & -1.63 \\
Human Resource & 4.13 & 0.86 & 4.21 & 0.80 & -0.70 \\
Political & 3.81 & 0.97 & 4.07 & 0.74 & $-2.11^{*}$ \\
Symbolic & 3.87 & 0.95 & 4.03 & 0.84 & -1.20 \\
\hline
\end{tabular}

$* p<0.05$ 
Therefore, based on teacher perceptions, the hypothesis "there are statistically significant differences in means of the number of frames utilized by principals in high and low performing West Virginia elementary schools according to school location" was accepted for the political frame. Rural principals were statistically more likely to use the political frame than urban principals.

Table 4.11 presents frequency distribution of leadership styles used by principals by school location, urban versus rural. Among 27 principals evaluated by teachers, 19 Table 4.11

Frequency Distribution of Principals' Leadership Style by School Location

\begin{tabular}{|c|c|c|c|c|}
\hline \multirow[t]{2}{*}{ Category/Pattern } & \multicolumn{2}{|c|}{ Urban } & \multicolumn{2}{|c|}{ Rural } \\
\hline & Frequency & $\%$ & Frequency & $\%$ \\
\hline No-frame & 3 & 37.5 & 2 & 10.5 \\
\hline \multicolumn{5}{|l|}{ Single-frame } \\
\hline Structural & 1 & 12.5 & 1 & 5.3 \\
\hline Human Resource & 0 & 0.0 & 1 & 5.3 \\
\hline Political & 0 & 0.0 & 1 & 5.3 \\
\hline Sub-Total & 1 & 12.5 & 3 & 15.9 \\
\hline \multicolumn{5}{|l|}{ Paired-frame } \\
\hline Structural/Human Resource & 1 & 12.5 & 1 & 5.3 \\
\hline Structural/Political & 0 & 0.0 & 1 & 5.3 \\
\hline Sub-Total & 1 & 12.5 & 2 & 10.6 \\
\hline \multicolumn{5}{|l|}{ Multi-Frame } \\
\hline $\begin{array}{l}\text { Structural/Human Resource/ } \\
\text { Political }\end{array}$ & 0 & 0.0 & 1 & 5.3 \\
\hline $\begin{array}{l}\text { Structural/Human Resource/ } \\
\text { Political/Symbolic }\end{array}$ & 3 & 37.5 & 11 & 57.9 \\
\hline Sub-Total & 3 & 37.5 & 12 & 63.2 \\
\hline Total & 8 & 100.0 & 19 & 100.0 \\
\hline
\end{tabular}


were from rural schools and eight were from urban schools. In terms of teacher perceptions, about $63 \%$ of those principals from rural schools followed the multi-frame leadership approach compared to about $38 \%$ of the principals from urban schools. Teachers also reported that one principal from urban schools and two principals from rural schools used the paired-frame leadership approach, accounting for about $13 \%$ and $11 \%$ of the total number of participants for each group. Also, one principal from urban schools was reported as using the single-frame leadership approach, and three principals from rural schools were reported to adopt the same category. Among eight principals from urban schools, three or nearly $38 \%$ did not use any frames as compared to only two (about $11 \%$ ) of 19 principals from rural schools.

Question 6. Based on teacher perceptions, what are the differences in principals' frame utilization (structural, human resource, political, and symbolic) in high and low performing West Virginia elementary schools according to school size (small/medium/large)?

Small, medium, and large size schools were identified and selected for participation in this study. However, only schools in the small and medium size categories met the $40 \%$ or greater teacher participation rate required for analysis. Therefore, no large size schools were considered.

Table 4.12 shows mean differences in principals' utilization of leadership frames reported by teachers by school size. The means of the utilization of all four frames by principals from small schools were higher than the means for those from medium size schools. However, the $t$ test analysis only indicated that there was a statistically significant difference in utilization of the human resource frame by principals in small 
and medium size schools, $t=2.66, p<0.01$. Teachers from small schools perceived their principals to be significantly more likely to use the human resource frame than principals from medium size schools.

Table 4.12

Difference in Principals' Utilization of Leadership Frames Reported by Teachers by School Size

\begin{tabular}{lccccl}
\hline \multirow{2}{*}{ Leadership Frame } & \multicolumn{2}{c}{ Small $(\mathrm{N}=85)$} & \multicolumn{2}{c}{ Medium $(\mathrm{N}=111)$} & \multirow{2}{*}{$t$} \\
\cline { 2 - 5 } & Mean & SD & Mean & SD & \\
\hline Structural & 4.25 & 0.71 & 4.05 & 0.84 & 1.78 \\
Human Resource & 4.36 & 0.68 & 4.05 & 0.89 & $2.66^{* *}$ \\
Political & 4.08 & 0.80 & 3.92 & 0.84 & 1.34 \\
Symbolic & 4.12 & 0.74 & 3.88 & 0.95 & 1.91 \\
\hline$* * 00.01$ & & & & &
\end{tabular}

Therefore, based on teacher perceptions, the hypothesis "there are statistically significant differences in means of the number of frames utilized by principals in high and low performing West Virginia elementary schools according to school size" was accepted for the human resource frame. Small size school principals were statistically more likely to use the human resource frame than medium size school principals.

As shown in Table 4.13, among 15 principals from small schools, 10 or two thirds followed the multi-frame leadership approach as compared to five of 12 principals (about $42 \%$ ) from medium size schools who followed the same approach. Teachers also reported that two of 15 principals from small schools adopted a paired-frame leadership style, while only one of 12 principals from medium size schools used the same leadership style. Together, those from small schools who used either a paired-frame leadership style or a multi-frame leadership style account for about $80 \%$, while those from medium size schools who used either of these two approaches only account for about $50 \%$. In 
addition, one principal from small schools used the single-frame leadership style and two did not consistently use any frame; three principals from medium size schools followed the no-frame leadership style and three followed the single-frame leadership style.

Table 4.13

Frequency Distribution of Principals' Leadership Style by School Size

\begin{tabular}{lcccc}
\hline \multicolumn{1}{c}{ Category/Pattern } & \multicolumn{2}{c}{ Small } & \multicolumn{2}{c}{ Medium } \\
\cline { 2 - 5 } & Frequency & $\%$ & Frequency & $\%$ \\
\hline No-frame & 2 & 13.3 & 3 & 25.0 \\
Single-frame & & & & \\
$\quad$ Structural & 0 & 0.0 & 2 & 16.7 \\
Human Resource & 1 & 6.7 & 0 & 0.0 \\
Political & 0 & 0.0 & 1 & 8.3 \\
Sub-Total & 1 & 6.7 & 3 & 25.0 \\
Paired-frame & & & & \\
Structural/Human Resource & 1 & 6.7 & 1 & 8.3 \\
Structural/Political & 1 & 6.7 & 0 & 0.0 \\
Sub-Total & 2 & 13.4 & 1 & 8.3 \\
Multi-Frame & & & & 8.3 \\
Structural/Human Resource/ & 0 & 0.0 & 1 & 33.3 \\
Political & & & & 41.6 \\
Structural/Human Resource/ & 10 & 66.7 & 4 & \\
Political/Symbolic & & & & \\
Sub-Total & 10 & 66.7 & 5 & \\
Total & 15 & 100.0 & 12 & \\
\hline
\end{tabular}

\section{Summary}

In summary, West Virginia elementary school principals considered in this study were more likely to use a multi-frame leadership approach, followed by a no-frame, a single-frame, and a paired-frame approach. There was a statistically significant difference in the utilization of the four leadership frames between principals from high 
performing and low performing schools. Principals from high performing schools were more likely to use all four leadership frames. Also, principals from high performing schools were more likely to adopt a multi-frame leadership style than their counterparts from low performing schools. Female principals were statistically significantly more likely to use the human resource frame and also a little more likely to follow a multiframe leadership approach than males. Principals' administrative experience did not have a significant effect on principals' use of the four leadership frames, but based on descriptive statistics, principals with less administrative experience ( $0-5$ years) were more likely to use the multi-frame leadership approach, while those principals with 6-10 years of administrative experience were more likely to use no-frame leadership. School location had a significant influence on principals' use of the political frame. Those from urban schools were significantly less likely to use the political frame than their counterparts from rural schools. Also, principals from rural schools were more likely to use the multiple frame leadership style than principals from urban schools. School size had a significant influence on principals' use of the human resource frame. Principals from small size schools were more likely to use this frame than their counterparts from medium size schools. Principals from smaller schools were more likely to use the multiframe leadership approach than their counterparts from medium size schools, while those from medium size schools were more likely to use the no-frame, single-frame, and paired-frame leadership styles than principals in small size schools. 


\section{Chapter Five}

\section{Conclusions and Recommendations}

Chapter five presents a summary of the study, findings, conclusions, and recommendations based on the findings relevant to leadership styles of principals in high and low performing West Virginia elementary schools as perceived by teachers. This chapter is divided into four sections: summary of the study, discussion of findings, conclusions, and recommendations.

\section{Summary of the Study}

The conceptual framework for this study is based on Bolman and Deal's (1984) four frame leadership orientation model (structural, human resource, political, and symbolic). The structural frame is associated with managing. It focuses on goals, specialized roles, formal relationships, rules, and rationality. The human resource frame emphasizes meeting the needs of its individuals, and it views the organization as a "family". The political frame defines the organization as having competitions for scarce resources, being fraught with conflict because of varied individual and group needs, and leveraging power through negotiation and compromise. The symbolic frame sees the organization as a culture that is inspired and driven by rituals, ceremonies, heroes, and stories. The four frames define organizational structures, behaviors, and governance patterns. According to Bolman and Deal (2003), earnest implementation of the frames in leadership practices increases the likelihood of achieving goals and desired outcomes.

This study examined teacher perceptions of principal leadership in high and low performing West Virginia elementary schools according to Bolman and Deal's four frame leadership model. In this study, high performing schools exhibit high levels of 
student achievement and low performing schools exhibit low levels of student achievement as measured by the West Virginia summative assessment of student achievement, the WESTEST. Further, this study looked at differences in frame utilization by principals in high and low performing elementary schools in regard to gender, administrative experience, school location, and school size.

\section{Discussion of Findings}

The findings presented in this section are based on the results of the analysis of data received in the teacher survey process regarding the six research questions guiding this study.

\section{General Patterns of Principals' Leadership Styles}

Question 1. Based on teacher perceptions, what are the leadership styles of principals in high and low performing West Virginia elementary schools as measured by the four frames (structural, human resource, political, and symbolic)?

This study sought to determine the frame utilization of principals in high and low performing West Virginia elementary schools. According to teacher perceptions, the 27 principals in high and low performing schools considered in this study were more likely to use the structural and human resource frames and less likely to use the political and symbolic frames in their leadership. Messer (2002), in her study of frame usage of 431 Florida elementary principals and Ulrich (2004), in her study of 13 high performing California high school principals' leadership styles, found the structural and human resource frames to be the most widely used as well.

This study sought to determine if principals in high and low performing West Virginia elementary schools were using no-frame, single-frame, paired-frame, or multiple 
frame leadership according to teacher perceptions. West Virginia elementary school principals considered in this study were more likely to use a multi-frame leadership approach, followed by a no-frame, a single-frame, and a paired-frame approach. The frequency distribution of frames utilized by the 27 principals considered in this study indicates that $18.5 \%$ were identified as not using any of the frames (no-frame) in their leadership. The findings of this study were somewhat lower than previous leadership studies. In Lewis-Stankus' (2007) study of principal leadership in schools with smaller learning communities, $49 \%$ were identified with the no-frame leadership approach. In Bowen's (2004) research on frame usage by county extension program coordinators, 39\% were identified with no-frame leadership style. In Chang's (2004) research on frame usage by college department chairs, $57 \%$ were identified with no leadership style. Bolman and Deal (2003) indicate that leaders lacking identification with a specific leadership frame may have difficulty viewing the organization from varied perspectives, thus handicapping their ability to address the many challenges they encounter.

Approximately $15 \%$ of the principals in both the high and the low performing school categories were identified as utilizing a single-frame in their leadership. Singleframe principals were associated with the structural, human resource, and political frames. Structural leadership is sometimes identified as managerial in nature. The structural principal gives attention to data and analysis in developing policies and procedures to address school issues. The human resource principal focuses on meeting the needs of individuals within the school to produce positive outcomes. The political 
principal is an advocate for the school who builds coalitions for success (Bolman \& Deal, 2003).

In a study of principal leadership and schools with small learning communities, Lewis-Stankus (2007) found results similar to the current study, $11 \%$ of the principals employed the single-frame method of leadership. Bensimon (1987), in a study of college presidents' frame usage, found that $41 \%$ were identified with a single-frame.

Paired-frame leadership was associated with $11 \%$ of the principals considered in this study. Two principals (7\%) were identified as using the structural and human resource frames, and one principal (4\%) was identified as utilizing the structural and political frames.

Lewis-Stankus (2007) in her study of principal leadership in schools with smaller learning communities found $9 \%$ of the principals to be paired-frame leaders (structural and political). Bowen (2004) found $15 \%$ to be paired-frame leaders and Chang (2004) found $14 \%$ to be paired-frame leaders.

Multi-frame leadership, the use of three of the four frames or all four frames, was associated with $56 \%$ of the principals in high and low performing schools in this study. Perhaps, teachers participating in this study perceive their principals as multi-frame leaders because the principal (generally the sole administrator in the school) is observed managing multiple issues in multiple roles - academics, instruction, student affairs, personnel matters, finance, and community relations on a daily basis.

Other studies found principals' utilization of multi-frame leadership as follows: Messer (2002) - 60\% and Lewis-Stankus (2007) - 31\%. Bowen (2004) found $12 \%$ of county extension program coordinators to be multi-frame leaders, and Chang (2004) 
found $15 \%$ of college department chair persons to be multi-frame leaders. Bensimon (1987) found $22 \%$ of college presidents utilizing multiple frames in their leadership. Bolman and Deal (2003) indicate that principals exhibiting multi-frame leadership styles are providing effective leadership. They further emphasize that using multiple frames provides the leader with greater ability to view the organization from multiple perspectives.

Question 2. Based on teacher perceptions, what are the differences in the number of frames utilized (no, single, paired, and multiple) by principals in high and low performing West Virginia elementary schools?

This study looked at differences between principals from high performing and low performing West Virginia elementary schools in utilizing the four leadership frames (structural, human resource, political, and symbolic). There were statistically significant differences in leadership styles between principals in high and low performing schools across all four frames. Principals in high performing schools were more likely to utilize the structural, human resource, political, and symbolic frames in their leadership than principals in low performing schools.

In this study, data indicated frame usage, according to teacher perceptions of principals' leadership in high performing schools, in descending order as follows: structural, human resource, political, and symbolic. Fleming (2002) found the same order of frame usage in her study of teacher perceptions of principals' leadership in Comprehensive School Reform Demonstration (CSRD) and Non-CSRD schools. Fears (2004), in his study of high and low performing elementary schools in one mid-Atlantic 
state, concluded that according to principals, teachers, and support staff, principals in high achieving schools were focusing their attention equally on all four frames.

Teacher perception mean scores for principal leadership in high performing schools in this study were substantially higher for the structural and human resource frames. Messer (2002), in her study of frame usage of 431 Florida elementary principals and Ulrich (2004), in her study of 13 high performing California high school principals' leadership styles, found the structural and human resource frames to be the most widely used as well. Eckley (1997), in a study of the relationship between teacher empowerment and principal leadership, found that teachers felt empowered as a group when the principal was perceived to be using the structural leadership style, and teachers felt empowered individually when the principal was perceived to be using the human resource leadership style.

In this study, the mean scores of teacher perceptions for principals' leadership in low performing schools in descending order were: human resource, structural, symbolic, and political. Similar results were found in Bista's (1994) study of college presidents human resource, symbolic, structural, and political. In Bista's study, the means were extremely close in the symbolic and structural frame, 3.58 and 3.56 respectively.

Further analysis of frame utilization data indicates that principals in high performing schools were using all four frames as leaders while principals in low performing schools were using only the human resource frame. Human resource as a dominant leadership orientation of principals in both high and low performing schools indicates a propensity to balance the needs of the organization with the needs of the individuals in the organization. The emphatic focus is concentrated on supporting and 
growing individuals, building relationships and morale, and involving individuals in the management process (Bolman \& Deal, 1992; Bista \& Glasman, 1998; Louis \& Marks, 1998; Leithwood \& Jantzi, 2000; Hallinger, 2003; WVDE, 2006).

According to Bolman and Deal (2003), successful leaders give attention to developing and maintaining a positive organizational culture. The four frames, each with its own unique focus, play a crucial role in nurturing and sustaining the organization's culture. The structural leader aligns structural frame components with the organization's culture and devises plans and opportunities for celebrating short term victories. The human resource leader solicits input from people throughout the organization and creates a team that focuses on developing, maintaining, and nurturing culture. The political leader creates arenas that focus on building alliances to enhance the organization's culture and invests resources and power to ensure success and celebration. The symbolic leader tells the story of the organization's culture through creating a positive vision of the future that is rooted in the organization's past history. Evidence from this study suggests that principals in high performing West Virginia elementary schools are giving attention to developing positive cultures in their schools by using all four frames in their leadership (p. 386-387).

Data from this study further indicated that principals from high performing West Virginia elementary schools $(85 \%)$ were far more likely to adopt the multi-frame leadership style than their counterparts from low performing West Virginia elementary schools (29\%). This is contrary to Fears' (2004) study in which he concluded high and low performing elementary principals used the four frames similarly, according to teacher perceptions. Fleming (2002), in a study of CSRD schools and Non-CSRD schools, found 
that teachers in CSRD schools rated their principals statistically significantly higher in frame utilization across the four leadership frames. Poniatowski (2006), in her study of the relationship between student achievement and principal leadership in 42 Florida elementary and secondary schools, found that elementary principals (59\%) and secondary principals $(90 \%)$ demonstrated the multi-frame leadership style on a regular basis.

According to Bolman and Deal (2002), leaders of high performing successful organizations must understand and effectively utilize all four frames in order to produce positive results. The essence of a school's existence is to produce positive student results, particularly in the area of academic achievement (high performing schools). The predominance of principals in high performing schools in this study perceived by teachers to be multi-frame leaders (all four frames) is testimonial to Bolman and Deal's four frame leadership model. Conversely, principals in low performing schools in this study were perceived by teachers to be no-frame, single-frame, or paired-frame leaders. Thus, principals in low performing schools would benefit from in depth trainings focusing on the concept of each frame, how each frame is used effectively in leadership practices, how the frames are interconnected, and how the frames provide different lenses for analyzing and handling school improvement.

\section{Demographic Effect on Principals' Leadership Styles}

Question 3. Based on teacher perceptions, what are the differences in principals' frame utilization (structural, human resource, political, and symbolic) in high and low performing West Virginia elementary schools according to gender?

According to teacher perceptions, there was a statistically significant difference between male and female West Virginia elementary principals in utilization of the human 
resource frame. Female principals were statistically higher than male principals in the human resource frame. Teachers participating in this study may perceive female principals to be more caring, more supportive, and more people oriented than male principals. Gilligan (1982), in her research on how people make decisions about morality, describes females as having a keen sense of responsibility for others, thus morality requires caring for others; males are described as having a keen sense of respect for the rights of others, thus morality limits one's actions toward others.

Female principals in this study were a little more likely to use the multi-frame leadership approach than male principals. Thompson (2000) studied perceived gender leadership differences of leaders in secondary and postsecondary educational institutions utilizing Bolman and Deal's four frame model. Thompson's study substantiated the findings of Bolman and Deal's (1992) research which found no significant difference in leadership between men and women in comparable positions. Lewis-Stankus (2007) found that female principals $(41 \%)$ in smaller learning community schools were somewhat more likely to be identified as multi-frame leaders than male principals $(26 \%)$. In contrast to the current study, Chang's (2004) study found $70 \%$ of female faculty chairs identified with the no-frame leadership approach.

Question 4. Based on teacher perceptions, what are the differences in principals' frame utilization (structural, human resource, political, and symbolic) in high and low performing West Virginia elementary schools according to the number of years of administrative experience $(0-5,6-10$, greater than 10$) ?$

In this study, years of administrative experience did not have a significant effect on principals' use of the four leadership frames. Fleming (2002) found no significant 
difference in use of the four leadership frames between urban and rural CSRD schools based on administrative experience. Lewis-Stankus (2007), in her study of principal leadership in smaller learning community schools, found no significant relationship between principals' leadership styles and years of administrative experience.

Based on descriptive statistics in this study, principals with less administrative experience (0-5 years) were more likely to use the multi-frame leadership approach, while principals with 6-10 years of administrative experience were more likely to use noframe leadership. Chang (2004) found college chairpersons with greater years of experience were most likely to be no-frame leaders. Both studies are contrary to Bensimon's (1989) study which found that new college presidents were more likely to be single-frame leaders, and more experienced college presidents were more likely to be paired-frame or multi-frame leaders.

Lewis-Stankus (2007) discovered no statistically significant difference in student achievement between principals with differing levels of experience (greater than 11 years of administrative experience compared to less than11 years). Messer (2002) found principals with 8-11 years of administrative experience multi-framed more frequently than principals with 0-3 years of administrative experience, and principals with 0-3 years used the structural frame more frequently than the other levels of administrative experience.

It is expected that greater administrative experience for principals would yield the larger percentage of principals using the multi-frame leadership style. However, in this study principals with less administrative experience (0-5 years) were more likely to use the multi-frame leadership style than principals with greater years of experience. Perhaps 
this results from involvement in the West Virginia Principals' Institute which focuses on providing a year long, in-depth professional development experience for principals. The thrust of the institute is to develop leadership skills necessary to transform schools into engaging and rigorous 21 st century learning environments for both students and staff (WVDE, 2008). In addition, consistent with Bensimon's (1989) findings, principals in this study with the most administrative experience also exhibited multi-frame styles.

Question 5. Based on teacher perceptions, what are the differences in principals' frame utilization (structural, human resource, political, and symbolic) in high and low performing West Virginia elementary schools according to school location (urban/rural)?

School location had a significant influence on principals' use of the political frame. Those from urban schools were significantly less likely to use the political frame than their counterparts from rural schools. Fleming (2002) found no significant differences across the four frames when comparing urban and rural CSRD principals' leadership, and significant differences across all four frames when comparing urban and rural Non-CSRD schools.

According to teacher perceptions, rural school principals were more likely to use the political frame than urban school principals. Many West Virginia schools are located in impoverished rural settings, isolated from the influences, assistance, and support found in more densely populated areas. Thus, rural schools by necessity must compete for scarce resources in their communities and districts in order to be successful.

According to this study, principals from rural schools were more likely to use the multiple frame leadership style than principals from urban schools. Lewis-Stankus (2007) found that principals in smaller learning community schools located in rural areas 
(other than city locations) were somewhat more likely to multi-frame than principals located in cities.

Question 6. Based on teacher perceptions, what are the differences in principals' frame utilization (structural, human resource, political, and symbolic) in high and low performing West Virginia elementary schools according to school size (small/medium/large)?

In this study, school size had a significant influence on principals' use of the human resource frame. Principals from small size schools were more likely to use the human resource frame than their counterparts from medium size schools. Teachers in small size schools may enjoy a closer sense of community, perceiving their principals as more caring, supportive, and people oriented; small schools may provide greater opportunities for principal and teacher interactions. Messer (2002), in her study of 431 Florida elementary school principals to determine differences in their use of the four frames, found no significant differences in utilization of the four frames based on school size.

According to this study, principals from small size schools were more likely to use the multi-frame leadership approach than their counterparts from medium size schools. Principals from medium size schools were more likely to use the no-frame, single-frame and paired-frame leadership styles than principals from small size schools. Lewis-Stankus (2007) found the same results for small and medium size schools in her study of principal leadership in schools with smaller learning communities. Chang (2004) found that college chairpersons in small and medium size departments were more likely to identify with no leadership style and chairpersons in large departments were 
more likely to identify with a leadership style (single-frame, paired-frame, or multiframe).

\section{Relationship of Individual Frames to Principal Leadership}

The Bolman and Deal (2003) four frame leadership model views organizations as factories (structural), families (human resource), jungles (political), and temples (symbolic). While none of the frames specifically address instructional leadership, the model's organizational focus does provide a framework for achieving positive outcomes in school principal leadership roles, the focus of this study.

The essence of a school's existence is to produce positive student outcomes, particularly in the area of academic achievement (relative to this study, a high performing school). According to Bolman and Deal (2002), the principal as the school leader must understand and effectively utilize the four individual frames in order to produce those positive results. Outcomes of this study indicate a significant relationship between principals' leadership in high performing West Virginia elementary schools and the use of each individual frame (structural, human resource, political, and symbolic) in their leadership.

Organizational productivity is the focus of the structural frame. In the educational setting, classrooms and schools function at optimal levels when there are clear goals and roles and when the endeavors of individuals and groups are well coordinated through policies, procedures, and established lines of authority. As the social architect, the structural principal analyzes and designs by emphasizing structure, strategy, and the environment (Bolman \& Deal, 2002). 
In regard to goals, the principal establishes goals that focus on reaching and maintaining high levels of student achievement, and keeps those goals in the forefront of the school's attention. If reaching those levels requires change, the principal ensures that change efforts are aimed clearly at key instructional components: curriculum, instruction and assessment practices.

Curriculum: The principal sets a goal to have the school's curriculum aligned with the state's content standards and objectives (CSOs) in all subject areas by the end of the school year. In another action regarding the curriculum, the principal monitors and observes the implementation of new programs and initiatives.

Instruction: The principal sets a goal to provide effective staff development regarding effective instructional practices. Elmore (2000) maintains that, "heavy investments in highly targeted professional development for teachers and principals in the fundamentals of strong classroom instruction" (p. 28) are critical to a school's success (Marzano, Waters, \& McNulty, 2005). Nunnelley, Whaley, Mull, and Hott (2003) state that "the principal is obligated to making sure strong professional growth plans are enacted" (p. 56).

Assessment: The principal sets a goal that the percent of students making adequate yearly progress will increase by a certain percent in a designated curricular area. In addition, the principal implements the use of standards-based report cards and gleans data from those reports to assess the school's effectiveness in attaining its goal to increase the number of students meeting or exceeding standards.

In the human resource frame, the principal focuses on the importance of individual needs and motives. In this frame, schools function best when individual needs 
are addressed in a trusting and caring environment. Commitment and involvement flourish in a work atmosphere that demonstrates concern for others, provides opportunity for participation, and shares in the decision making process. The leader in the human resource frame is an enabler who empowers and supports others. He is a servant who shares information and knowledge, and is visible and accessible.

The human resource principal creates a caring environment by taking an interest in the personal lives of teachers and staff. He is aware of their personal needs and acknowledges major events in their lives (births, deaths in family, weddings, etc). The principal makes it a priority to maintain personal relationships with teachers and staff. Fullan (2001) emphasizes the importance of the principal forming emotional bonds with the staff. He contends that these bonds provide stability and focus during times of crisis and uncertainty.

In regard to providing input and meeting needs, Marzano, Waters, McNulty (2005) indicate that the principal "provides teachers with materials and professional development resources necessary for the successful execution of their duties" (p. 60). This is evidenced when he regularly meets with every teacher to ascertain their needs, and when he schedules trainings they have specifically requested.

The principal supports teachers in their endeavors to positively impact student achievement by directly involving them in the design and implementation of curriculum, instruction, and assessment activities. For example, he meets with teachers seeking their input on the effectiveness and possible modification of bench marking measures. Also, the principal meets with subject department teams to discuss how they will address the content of their subject as it relates to state standards and assessment measures. 
"The research has demonstrated the great need for strong instructional leadership in schools and has identified several common characteristics of effective leaders. One of those characteristics, extremely important in the life of a school and often neglected is that of being a visible principal" (Whitaker, 1997, p. 155). Visibility and accessibility are evidenced by the principal's contacts and interactions with staff, students, and community.

The proposed effect of visibility is twofold: first, it communicates the message that the principal is interested and engaged in the daily operations of the school; second, it provides opportunities for the principal to interact with teachers and students regarding substantive issues. (Marzano, Waters, \& McNulty, 2005, p. $61)$.

"The political frame emphasizes the allocation of power and scare resources through the use of power, conflict, competition, and positive politics" (Fears, 2005, p. 44). In this scenario, schools are arenas in which groups and individuals jockey for power and where conflict is ever present. Goals emerge from the give and take of compromise over scarce resources. The principal as political leader is an advocate for the school who builds coalitions for success. He monitors the power structures and builds linkages to stakeholders. He uses persuasion and negotiation to get things done.

Marzano, Waters, and McNulty (2005) hold that resources are to a school as food is to the body. Fullan (2001) indicates that, "another component of school capacity concerns the extent to which schools garner technical resources. Instructional improvement requires additional resources in the form of materials, equipment, space, 
time, and access to new ideas and to expertise" (pp. 64-65). Many of these resources are vital and scarce in the school setting.

The principal in the political frame understands the competition for resources and constantly seeks workable solutions. This is the case when the principal addresses the scheduling of limited technology resources to meet the instructional demands required of all teachers in the technology-dependent learning environment.

The symbolic frame focuses on the organization's culture and beliefs. Schools create symbols to engender commitment, hope, and loyalty. These symbols are reflected in stories, metaphors, ceremonies, and rituals. The symbolic leader is thought of as a prophet who uses symbols to capture attention.

The symbolic principal uses this frame to focus on team building, team spirit, and to unify teachers through creating a community of believers joined by shared faith and culture (Lewis-Stankus, 2007). Designing a faculty meeting within the symbolic frame, the principal designates a committee presentation to highlight the school's mission statement and its impact on instruction and student achievement. Also, the presentation is to identify school traditions that symbolize the school's focus on instruction and student achievement. The goal of the presentation is to refocus teachers' attention on their main purpose, generate new excitement about teaching and learning, and communicate a strong and challenging sense of purpose (Fears, 2005).

This section has focused on the effective implementation of Bolman and Deal's four frame leadership orientation model in the school setting. A thorough knowledge of the four frames and a solid understanding of how and when to utilize them effectively would greatly benefit principals in low performing West Virginia elementary schools. 


\section{Conclusions}

In conclusion, this study has provided insight into the principal leadership landscape in WV elementary schools. This study has identified significant differences in frame utilization between principals in high and low performing WV elementary schools:

- $\quad$ principals in high performing schools were significantly more likely to use all four frames than principals in low performing schools;

- female principals were significantly more likely to use the human resource frame than male principals;

- rural principals were significantly more likely to use the political frame than urban principals; and

- principals in small size schools were significantly more likely to use the human resource frame than principals in medium size schools. In regard to leadership styles, the multi-frame style is deemed by Bolman and Deal (2003) to be most ideal for producing positive organizational outcomes. They indicate that principals exhibiting the multi-frame leadership style are providing effective leadership in their schools. This study found the following groups of WV elementary school principals using multiple frames in their leadership:

- principals in high performing schools;

- female principals;

- principals with 0-5 years of administrative experience;

- $\quad$ rural principals; and

- $\quad$ principals in small size schools. 
Thus, based on the outcomes of this study, it appears that the principal leadership landscape of West Virginia elementary schools would be improved further by implementing the Bolman and Deal four frame leadership model, particularly with principals in low performing schools and principals identified as no-frame, single-frame, and paired-frame leaders.

\section{Recommendations}

\section{Recommendations for Practice}

As stated in Chapter One, there is urgent need for an instructional leadership focus on increasing academic performance to equip students for the global competition we now encounter. In order to meet the instructional leadership demands of our day, potential principals must be "tooled" and existing principals must be "retooled" with instructional leadership practices that focus on positive student academic outcomes. The following recommendations are made toward that end.

1. School districts should provide an in depth training program focusing on a thorough presentation of the Bolman and Deal four-frame leadership model for principals and potential principals. Training would instill awareness of the appropriate circumstances for using each of the four frames (structural, human resource, political, and symbolic) as well as the benefits of using multiple frames for effective leadership results.

2. School districts should require an annual assessment of principal leadership utilizing the Bolman and Deal Leadership Orientation (Self) and (Other) survey instrument. This would allow principals to annually analyze selfperceptions of their leadership practices across the four frames (structural, 
human resource, political, and symbolic) and compare those perceptions with the perceptions of others with whom they work. It would provide opportunity for the principal to identify strengths and weaknesses in frame utilization as perceived by self and others, and it would shed light on areas where improvements need to occur.

3. School districts should provide a system of support for principals in implementing effective instructional leadership practices. This could be facilitated through the use of mentors who know, understand, and utilize Bolman and Deal's four frame leadership orientation model. Mentors would work with new or struggling principals to assist them in enhancing their leadership skills.

\section{Recommendations for Future Research}

As with most research, the findings raise many questions that require continued investigation. The following recommendations are offered to guide researchers in the continuation of this line of study.

1. This study should be replicated in other states to determine if the findings of teacher perceptions of principal leadership in West Virginia elementary schools are consistent elsewhere.

2. This study should be replicated in West Virginia to determine if differences between principals' leadership styles and frame utilization in high and low performing schools remain consistent with this study.

3. This study should be replicated in West Virginia high schools and middle schools to determine if differences between principals' leadership styles and 
frame utilization in high and low performing schools remain consistent with this study of elementary schools.

4. This study should be replicated and expanded to determine the perceptions of others (superintendents, immediate supervisors, support staff, and parents) about principals' leadership styles and frame utilization. This would explore data from different perspectives of interactions with the principal.

5. Qualitative studies that probe the specific behaviors, settings, and issues of principal leadership in high and low performing West Virginia elementary schools would be beneficial for a deepened understanding of the dynamics within those schools.

6. Qualitative studies of teacher/principal relationships would be beneficial in understanding differences in principals' leadership between high and low performing West Virginia elementary schools.

7. Findings of this study indicate principals with the least years of administrative experience were more likely to use the multi-frame leadership style than principals with 6-10 years of experience. Further studies should be conducted to determine if the same effect occurs.

8. Female principals were significantly more likely to use the human resource frame, and tended to use multiple frames in their leadership as opposed to males. A gender study across the demographic variables of years of administrative experience, school location, and school size would provide insight into potential leadership differences between male and female principals. 


\section{References}

Adams, A. S., Soumerai, S. B., Lomas, J., \& Ross-Degnan, D. (1999). Evidence of selfreport bias in assessing adherence to guidelines. International Journal for Quality in Health Care, 187-192.

Andrews, R. L., \& Soder, R. (March, 1987). Principal leadership and student achievement. Educational Leadership, 44(6), 9-11.

Barth, R. (1986). On sheep and goats and school reform. Phi Delta Kappan, 68(4), 293296.

Barth, R. (2001). Learning by heart. San Francisco, CA: Jossey-Bass.

Bass, B. M. (1990). Bass and Stogdill's handbook of leadership (3rd. ed.). New York: Free Press.

Bensimon, E. M. (1987, November). The meaning of "good presidential leadership": A frame analysis. (ASHE Annual Meeting). Washington, DC: Office of Educational Research and Improvement (ED).

Bensimon, E. M. (1989). The meaning of "good presidential leadership": A frame analysis. Review of Higher Education, 12(2), 107-123.

Bensimon, E. M. (1990). Viewing the presidency: Perceptual congruence between presidents and leaders on their campuses. Leadership Quarterly, 1(2), 71-90.

Birnbaum, R. (1988). How colleges work: The cybernetics of academic organization and leadership. San Francisco, CA: Jossey-Bass.

Birnbaum, R. (1992). How academic leadership works: Understanding success and failure in the college presidency. San Francisco, CA: Jossey-Bass.

Bista, M. B. (1994). Determinants and effects of the structural, human resource, 
political and symbolic leadership styles of school principals. Unpublished Ph.D. Dissertation, University of California, Santa Barbara.

Bista, M. B., \& Glasman, N. S. (1998). Principals' perceptions of their approaches to organizational leadership: Revisiting Bolman and Deal. Journal of School Leadership 8(1), 26-48.

Blake, R. R., \& Mouton, J. S. (1985). The managerial grid iii. Houston, TX: Gulf. Blanchard, K. (1996). Turning the organization upside down. In F. Hesselbein, M. Goldsmith, \& R. Beckhard (Eds.), The leader of the future (pp. 81-88). San Francisco, CA: Jossey-Bass.

Blasé, J., \& Blasé, J. (1999). Principal's instructional leadership and teacher development: Teachers' perspectives. Educational Administration Quarterly, 35(3), 349-378.

Bogler, R. (2001). The influence of leadership style on teacher job satisfaction. Educational Administration Quarterly, 37(5), 662-683.

Bolman, L. (1990). Research with leadership orientations instrument. Retrieved July 29, 2008 from http://www.leebolman.com/orientations.htm.

Bolman, L. G., \& Deal, T. E. (1984). Modern approaches to understanding and managing organizations. San Francisco: Jossey-Bass.

Bolman, L. G., \& Deal, T. E. (1991). Reframing Organizations. San Francisco: JosseyBass.

Bolman, L. G., \& Deal, T. E. (1992). Leading and managing: Effects of context, culture, and gender. Educational Administration Quarterly, 28(3), 314-329.

Bolman, L. G. \& Deal, T. E. (2002). Reframing the path to school leadership: A guide for 
teachers and principals, Thousand Oaks, CA: Corwin Press, Inc.

Bolman, L. G., \& Deal, T. E. (2003). Reframing organizations: Artistry, choice and leadership (3rd. ed.). San Francisco: Jossey-Bass.

Bowen, E. (2004). Perspectives on the leadership styles of west virginia university extension service county program coordinators. Dissertation, West Virginia University.

Brandt, R. (1987). On leadership and student achievement: A conversation with Richard Andrews. Educational Leadership, 45(1), 9-16.

Bulach, C., Lunenburg, F. C., \& McCallon, R. (1994, April). The influence of the principal's leadership style on school climate and student achievement. (American Educational Research Association Annual Meeting). New Orleans, LA.

Chang, T. (2004). Leadership styles of department chairs and faculty utilization of instructional technology. Dissertation, West Virginia University.

Coleman, J. (1966). On equality of educational opportunity. Washington, DC: US Department of Health, Education, and Welfare, Office of Education/National Center for Education Statistics.

Conley, D. T., \& Goldman, P. (1994). Ten propositions for facilitative leadership. In J. Murphy \& K. S. Louis (Eds.), Reshaping the principalship: Insights from transformational reform efforts (237-262). Thousand Oaks, CA: Corwin Press.

Council of Chief School Officers. (1996). Standards for school leaders. Interstate School Leader Licensure Consortium. Washington, DC: Author.

Cuban, L. (1984). Transforming the frog into a prince: Effective schools research, policy 
and practice at the district level. Harvard Educational Review, 54(2), 129-151.

Cunningham, W. G., \& Gresso, D. W. (1993). Cultural leadership. Boston, MA: Allyn and Bacon.

Day, C., Harris, A., \& Hadfield, M. (2001). Challenging the orthodoxy of effective school leadership. International Journal of Leadership in Education, 4(1), 39-56.

Deal, T. E., \& Peterson, K. D. (1990). The principals role in shaping school cultures. Washington, DC: United States Department of Education.

Donaldson, S. I., \& Grant-Vallone, E. (Winter, 2002). Understanding self-report bias in organizational behavior research. Journal of Business and Psychology, 17(2), 245-260.

Eckley, M. (1997). The relationship between teacher empowerment and principal leadership styles (school organization). Dissertation Abstracts International, 58, 2475.

Edmonds, R. (1979). Effective schools for the urban poor. Educational Leadership, $37(1), 15-28$.

Elmore, R. F. (2000). Building a new structure for school leadership. New York. Albert Shanker Institute.

Fears, A. (2004). A study of school-based leadership and the school improvement process for elementary schools that have demonstrated high and low student achievement. Dissertation Abstracts International, 66, 41A.

Federal Register (2001, March 28). Urban area criteria for census 2000. Part IV Department of Commerce Bureau of the Census. Retrieved September 27, 2008, from http://www.census.gov/geo/www/ua/ua_2k.pdf. 
Fielder, F. E. (1967). A theory of leadership effectiveness. New York: McGraw-Hill.

Fleming, N. (2002). A study of principal and teacher judgments of principal leadership orientation. Dissertation Abstracts International, 64, 1921A.

Fullan, M. (2001). Leading in a culture of change. San Francisco, CA: Jossey-Bass.

Fullan, M. (2002). The change leader. Educational Leadership, 59(8), 16-20.

Fullan, M. (2003). The moral imperative of school leadership. Thousand Oaks, CA: Corwin Press, Inc.

Gay, L. R., Mills, G. E., \& Airasian, P. (2006). Educational research: Competencies for analysis and applications (8th. ed.) Upper Saddle River, NJ: Pearson Prentice Hall.

Gilligan, C. (1982). In a different voice: Psychological theory and women's development. Cambridge, MA: Harvard University Press.

Glickman, C. (1989). Has Sam and Samantha's time come at last? Educational Leadership, 46(8), 4-9.

Gliner, J., \& Morgan, G. (2000). Research methods in applied settings: An integrated approach to design and analysis. Mahwah, NJ: Lawrence Erlbaum.

Goldman, P., \& Smith, N. (1991, June). Filling the frames: Using Bolman and Deal to analyze an educational innovation. Revision of a paper presented at the annual meeting of the Canadian Society for the Study of Education. Kingston, Ontario, Canada.

Griffith, J. (1999). The school leadership/school climate relation: Identification of school configurations associated with change in principals. Educational Administration Quarterly, 35(2), 267-291. 
Hallinger, P. (1992). The evolving role of American principals: From managerial to instructional to transformational leaders. Retrieved May 12, 2008 from http://proquest.umi.com.www.libproxy.wvu.edu/pqdweb?index $=3 \&$ sid= $1 \&$ srchm ode $=3 \& v$.

Hallinger, P. \& Leithwood, K. (1998). Unforseen forces: The impact of school culture on school leadership. Peabody Journal of Education, 73(2), 126-151.

Hallinger, P. (2003). Leading educational change: Reflections on the practice of instructional and transformational leadership. Cambridge Journal of Education, 33(3), 329-351.

Hallinger, P. (2005). Instructional leadership and the school principal: A passing fancy that refuses to fade away. Leadership and Policy in Schools, 4, 221-239.

Hallinger, P., Bickman, L., \& Davis, K. (1990, June). What makes a difference? School context, principal leadership, and student achievement. Occasional Paper No. 3 prepared for The National Center for Educational Leadership. Washington, DC. Office of Educational Research and Improvement (ED).

Harchar, R. L., \& Hyle, A. E. (1996). Collaborative power: A grounded theory of administrative instructional leadership in the elementary school. Journal of Educational Administration, 34(3), 15-29.

Hanson, M. (2001). Institutional theory and educational change. Educational Administration Quarterly, 37(5), 637-661.

House, R. J. (1971). A path-goal theory of leadership excellence. Administrative Science Quarterly, 16, 321-338.

Hoy, W. K., \& Miskel, C. G. (2005). Educational administration: Theory, research and 
practice (7th. ed.). Boston: The McGraw-Hill Companies.

Institute for Educational Leadership. (2000). Leadership for student learning:

Reinventing the principalship. Washington, DC: Author.

Jackson, D. (2000). The school improvement journey: perspectives on leadership. School Leadership \& Management, 20(1), 61-78.

Kniewel, V. (1999). Leadership orientation of principals and teacher participation in decision-making. Dissertation Abstracts International, 60, 3219A.

Kotter, J. (1996). Leading change. Boston, MA: Harvard Business School.

Kotter, J. P., \& Cohen, D. S. (2002). The heart of change: Real life stories of how people change their organizations. Boston, MA: Harvard Business School.

Kouzes, J., \& Posner, B. (1996). Seven lessons for leading the voyage to the future. In F. Hesselbein, M. Goldsmith, \& R. Beckhard (Eds.), The leader of the future (pp. 99-110). San Francisco, CA: Jossey-Bass.

Leithwood, K. (1994). Leadership for school restructuring. Educational Administration Quarterly, 30, 498-518.

Leithwood, K., \& Jantzi, D. (1999). Transformational leadership effects: A replication. School Effectiveness and School Improvement, 4(10), 451-479.

Leithwood, K., \& Jantzi, D. (2000). Principal and teacher leader effects: A replication. School Leadership and Management, 20(4), 415-434.

Leithwood, K., Louis, K. S., Anderson, S., \& Wahlstrom, K. (2004). Review of research: How leadership influences student learning. New York, NY: The Wallace Foundation www.wallacefoundation.org.

Leithwood, K. A. \& Riehl, C. (2003). What do we already know about successful school 
leadership. Paper presented at the annual meeting of the American Educational Research Association, Chicago.

Leithwood, K., \& Steinbach, R. (2003). Toward a second generation of school leadership standards. In P. Hallinger (Ed.), Reshaping the landscape of school leadership development: A global perspective. Lisse, Netherlands: Swets \& Zeitlinger.

Lewis-Stankus, S. J. (2007). A study of the relationship between the leadership styles of principals in smaller learning communities, the number of structures and strategic configurations and the rates of student success of $9^{\text {th }}$ graders. Unpublished doctoral dissertation, West Virginia University, Morgantown.

Lezotte, L. (1994). Property of American Association of School Administrators. The nexus of instructional leadership and effective schools. Retrieved April 22, 2008 from http://findarticles.com/p/articles/mi_m0JSD/is_6_51/ai_77196246.

Lezotte, L. (2008a). Correlates of effective schools: The first and second generation. Retrieved April 18, 2008, from http://www.effectiveschools.com/down loads/ Correlates.pdf.

Lezotte, L. (2008b). Revolutionary and evolutionary: The effective schools movement. Retrieved April 18, 2008, from http://www.effectiveschools.com/down loads/ $\underline{\text { RevEv.pdf. }}$

Lezotte, L. W., \& Pepperl, J. C. (1999). The effective schools process: A proven path to learning for all. Okemos, MI: Effective Schools Products, Ltd.

Louis, K. S., \& Marks, H. (1998). Does professional community affect the classroom? American Journal of Education, 106(4), 532-575.

Marks, H. M., \& Louis, K. S. (1997). Does teacher empowerment affect the classroom? 
The implications of teacher empowerment for instructional practice and student academic performance. Educational Evaluation and Policy Analysis, 19(2), 245275.

Marks, H. M., \& Printy, S. M. (2003). Principal leadership and school performance: An integration of transformational and instructional leadership. Educational Administration Quarterly, 39(3), 370-397.

Marzano, R. J., Pickering, D. J., \& Pollock, J. E. (2001). Classroom instruction that works: Research-based strategies for increasing student achievement. Alexandria, VA: Association for Supervision and Curriculum Development.

Marzano, R. J., Waters, T., \& McNulty, B. A. (2005). School leadership that works: From research to results. Alexandria, VA: Association for Supervision and Curriculum Development.

Mendez-Morse, S. (1991). The principal's role in the instructional process: Implications for at-risk students. Southwest Educational Development Laboratory (SEDL) Issues About Change, 1(3), 1-4, 6.

Mendez-Morse, S. (1992). Leadership characteristics that facilitate change. Southwest Educational Development Laboratory (SEDL). Retrieved August 23, 2008 from http://www.sedl.org/change/leadership/history/html.

Messer, J. (2002). Elementary principal leadership orientation and selected professional and school variables. Dissertation Abstracts International, 63, 450A.

Murphy, J. (2002). Reculturing the profession of educational leadership: New blueprints. Educational Administration Quarterly, 38(2), 176-192.

Murphy, J., \& Shipman, N. (2003). Developing a standard for school leadership 
development: A process and rationale. In P. Hallinger (Ed.), Reshaping the landscape of school leadership development: A global perspective. Lisse, Netherlands: Swets \& Zeitlinger.

National Commission on Excellence in Education. (1983). A nation at risk: The imperative for educational reform. Washington, DC: United States Department of Education.

National Conference of State Legislatures. (2002). The role of school leadership in improving student achievement. Washington, DC: Author.

Nettles, S. M., \& Harrington, C. (2007). Revisiting the importance of the direct effects of school leadership on student achievement: The implications for school improvement policy. Peabody Journal of Education, 82(4), 724-736.

No Child Left Behind Act of 2001, Pub. L. No. 107-110, § 201, 115 Stat. 1425 (2002).

Nunnelley, J. C., Whaley, J., Mull, R., \& Hott, G. (2003). Brain compatible secondary schools: The visionary principal's role. Bulletin, 87(637), 48-59.

Peterson, K.D. \& Deal, T.E. (1998). How leaders influence the culture of schools. Educational Leadership, 56(1), 28-30.

Peterson, K.D. \& Deal, T.E. (1999). Shaping school culture: The heart of leadership. San Francisco, CA: Jossey-Bass.

Poniatowski, D. (2006). The relationship of student achievement to principals' selfreported use of the four frame theory. Dissertation Abstracts International, 67, 3254A.

Schlecty, P. (1997). Inventing better schools: An action plan for educational reform. San Francisco, CA: Jossey-Bass. 
Senge, P. (1990). The fifth discipline: The art \& practice of the learning organization. New York, NY: Currency Doubleday.

Shafritz, J., Ott, S., \& Yong, S. K. (2005). Classics of organization theory (6th. ed.). Belmont, CA: Thomson Wadsworth.

Southern Regional Education Board (SREB). (2002). SREB goals for education: Challenge to lead. Retrieved April 28, 2008 from http://www.sreb.org/main/ goals/2002_goals_report.pdf.

Southern Regional Education Board (SREB). (August, 2007). SREB leadership curriculum modules: Engaging leaders in solving real school problems. Retrieved April 28, 2008 from http://www.sreb.org/main/ Leadership/Modules/07V27_ leadership_curriculum_modules.pdf.

Stogdill, R. M. (1974). Handbook of leadership: A survey of theory and research. New York: Free Press.

Stogdill, R. M. (1981). Traits of leadership: A follow-up to 1970. In B. M. Bass (Ed.) Stogdill's Handbook of Leadership (73-97). New York: Free Press.

Thompson, M. D. (2000). Gender, leadership orientation, and effectiveness: Testing the theoretical models of bolman \& deal and quinn. Sex Roles, 42 (11/12), 969-992.

Ulrich, C. (2004). Leadership styles of high school principals in top performing California schools: Perceptions of stakeholders. Dissertation Abstracts International, 65, 2050A.

U.S. Congress, Senate Committee on Equal Educational Opportunity. (1977). Toward equal educational opportunity. Washington, DC: Government Printing Office.

U.S. Department of Education. No child left behind act of 2001. Retrieved April 28, 2008 
from http://www.ed.gov/policy/elsec/leg/esea02/index.html.

Wang, M. C., Haertel, G. D., \& Walbert, H. J. (1993). Toward a knowledge base for school learning. Review of Educational Research, 63, 249-294.

West Virginia Department of Education (WVDE). (Draft, 2005-2006). Framework for high performing elementary schools. WV Achieves.

West Virginia Department of Education (WVDE). (Revised July, 2006). Framework for high performing $21^{\text {st }}$ century school systems. WV Achieves.

West Virginia Department of Education (WVDE). West Virginia institutes for $21^{\text {st }}$ century leadership. Retrieved April 28, 2008 from http://wvde.state.wv.us/ principalsinstitute/.

West Virginia Department of Education (WVDE). School Report Cards. Retrieved October 8, 2009 fromhttp://wveis.k12.wv.us/nclb/pub/rpt0708/ pickreportcard.cfm.

West Virginia State Code §18A-2-9. http://www.legis.state.wv.us/WVCODE/Code.cfm. West Virginia State Code §18A-3-2a. http://www.legis.state.wv.us/WVCODE/Code.cfm. West Virginia State Code §18A-3-2c. http://www.legis.state.wv.us/WVCODE/Code.cfm. West Virginia State Code §18A-4-7a. http://www.legis.state.wv.us/WVCODE/Code.cfm. Whitaker, B. (1997). Instructional leadership and principal visibility. The Clearing House, 70(3), 155-156.

Yukl, G. (2002). Leadership in organizations (5th. ed.). Upper Saddle River, NJ: Prentice Hall. 


\section{APPENDIX A}

\section{Principal Questionnaire}

Each principal is asked to provide the following demographic data about themselves and their school.

1 How many teachers do you supervise at this school?

2 How many years have you served as principal at this school?

3 Gender: __ Male _ Female

4 Number of Years of Administrative Experience (include current year):

$$
(0-5 \text { years }) \quad(6-10 \text { years }) \quad \text { _ }(10 \text { years }+)
$$

5 In regard to location, which best describes your school?

Urban (located in city/town/area with a population greater than 2500)

Rural (located in city/town/area with a population less than 2500)

6 In regard to school size, which following best describes your school?

_ Small (0-200 students)

Medium (201-400 students)

Large (401-781 students)

I greatly appreciate your assistance in this endeavor.

Survey Number 


\section{APPENDIX B \\ LEADERSHIP ORIENTATIONS (OTHER)}

(C) 1990, Lee G. Bolman and Terrence E. Deal, all rights reserved

This questionnaire asks you to describe the person that you are rating in terms of leadership and management style.

\section{Leader Behaviors}

You are asked to indicate how often each item is true of the person that you are rating. Please use the following scale in answering each item.

\section{1-Never 2-Occasionally 3-Sometimes 4-Often 5-Always}

So, you would answer ' 1 ' for an item that is never true of the person you are describing, ' 2 ' for one that is occasionally true, ' 3 ' for one that is sometimes true, and so on.

Be discriminating! The results will be more helpful to the ratee if you think about each item and distinguish the things that the ratee really does all the time from the things that s/he does seldom or never.

1. Thinks very clearly and logically.

2.___ Shows high levels of support and concern for others.

3.___ Shows exceptional ability to mobilize people and resources to get things done.

4. Inspires others to do their best.

5.___ Strongly emphasizes careful planning and clear time lines.

6.___ Builds trust through open and collaborative relationships.

7. Is a very skillful and shrewd negotiator.

8.___ Is highly charismatic.

9.___ Approaches problems through logical analysis and careful thinking.

10.___ Shows high sensitivity and concern for others' needs and feelings.

11.___ Is unusually persuasive and influential.

12. ___ Is an inspiration to others.

13. ___ Develops and implements clear, logical policies and procedures.

14. ___ Fosters high levels of participation and involvement in decisions.

15. ___ Anticipates and deals adroitly with organizational conflict.

16. Is Is highly imaginative and creative.

17.___ Approaches problems with facts and logic.

18. ___ Is consistently helpful and responsive to others.

19.___ Is very effective in getting support from people with influence and power.

20.___ Communicates a strong and challenging vision and sense of mission.

21.___ Sets specific, measurable goals and holds people accountable for results.

22. _L_Listens well and is unusually receptive to other people's ideas and input.

23. I _ Is politically very sensitive and skillful.

24. Sees beyond current realities to create exciting new opportunities.

25. Has extraordinary attention to detail.

26. ___ Gives personal recognition for work well done.

27.___ Develops alliances to build a strong base of support.

28. ___ Generates loyalty and enthusiasm.

29. ___ Strongly believes in clear structure and a chain of command.

30. I _ Is a highly participative manager.

31.___ Succeeds in the face of conflict and opposition.

32. ___ Serves as an influential model of organizational aspirations and values. 


\section{APPENDIX C}

From: $\quad$ Lee Bolman [bolmanl@umkc.edu]

Sent: $\quad$ Saturday, April 05, 2008 1:37 AM

To: 'Gus Penix'

Subject: $\quad$ RE: Request for Permission

Dear Mr. Penix:

I am happy to offer you permission to use the Leadership Orientations Survey in your dissertation research, subject to your agreement to the conditions that you reference in your message.

Best wishes in your research, and we'll look forward to learning of your results.

Lee G. Bolman

Professor and Marion Bloch/Missouri Chair in Leadership

Bloch School of Business and Public Administration

University of Missouri-Kansas City

5100 Rockhill Road

Kansas City, MO 64110

Tel: (816) 235-5407

Fax: (816) 235-6529

Email: bolmanl@umkc.edu

Web site: www.leebolman.com

From: Gus Penix [mailto:gpenix@access.k12.wv.us]

Sent: Friday, April 04, 2008 3:54 PM

To: bolmanl@umkc.edu

Subject: Request for Permission

Dear Dr. Bolman,

I am a doctoral candidate at West Virginia University in Educational Leadership Studies. I am requesting your permission to use the Leadership Orientations (Other) survey instrument as part of my dissertation entitled "A Study of the Relationship between Leadership Styles of Principals and Student Achievement in West Virginia Elementary Schools." Your four frame model is the conceptual framework for my study of leadership styles. I accept the conditions under which you grant permission such as, making the results of my research available to you upon request. It is my hope that you will grant permission to continue this research. I thank you for considering this request.

Sincerely,

Gus Penix 


\begin{abstract}
APPENDIX D
From Lee Bolman <bolmanl@umkc.edu>

Date 2008/04/19 Sat AM 11:38:07 CDT

To pengus@verizon.net

Subject RE: Use of Survey

Dear Mr. Penix:

You have permission to use Zoomerang Survey Software to administer the Leadership Orientations Survey.

Best wishes.

Lee G. Bolman

Professor and Marion Bloch/Missouri Chair in Leadership

Bloch School of Business and Public Administration

University of Missouri-Kansas City

5100 Rockhill Road

Kansas City, MO 64110

Tel: (816) 235-5407

Fax: (816) 235-6529

Email: bolmanl@umkc.edu

Web site: www.leebolman.com

-----Original Message-----

From: pengus@verizon.net [mailto:pengus@verizon.net]

Sent: Saturday, April 19, 2008 7:01 AM

To: bolmanl@umkc.edu

Subject: Use of Survey

Dr. Bolman,

I wrote you on April 4, 2008, requesting use of the Leadership Orientations (Others) in my dissertation research. You kindly granted permission on April 5.

I am further requesting your permission to survey participating schools electronically using Zoomerang Survey software. Attached is a portion of how the Leadership Orientations (Others) survey will appear online. Should permission not be granted, the surveys will be administered by paper as per the original request.

Again, I thank you for your time and consideration in this matter.

Gus Penix
\end{abstract}




\section{APPENDIX E}

\section{WestVirginiaUniversity \\ College of Human Resources and Education}

Dear Principal:

This letter is a request for you to take part in a research project to assess principal leadership styles in West Virginia elementary schools. This project is being conducted by Gus Penix, a doctoral student in the Educational Leadership Studies Department of WVU. Your participation in this project is greatly appreciated and should take no more than five to seven minutes to complete the online questionnaire.

Your involvement in this project will be kept as confidential as legally possible. Surveys are nameless and data received for each school surveyed will be confidentially maintained and not released. All data will be reported in the aggregate. I will not ask any information that will lead back to your identity as a participant. Your participation is completely voluntary. You may skip any question that you do not wish to answer and you may discontinue at any time. WVU's Institutional Review Board acknowledgement of this project is on file.

I hope that you will participate in this research project, as it could be beneficial in providing data for potential use by the West Virginia Department of Education in planning and developing future leadership initiatives, and by higher education institutions in planning and developing leadership studies course work. Thank you very much for your time. Should you have any questions about this letter or the research project, please contact me at the following e-mail address, gpenix@access.k12.wv.us.

Guidelines for participating in the survey:

1) Access the online Principal's questionnaire at the following web address: http://www.zoomerang.com/Survey/?p=WEB228CMU.

2) Distribute the enclosed teacher participation letters to all full-time teachers in your school.

Thank you for your time and help with this project.

Sincerely,

GusPenix 


\section{APPENDIX F}

\section{WestVirginiaUniversity \\ College of Human Resources and Education}

Dear Teacher:

This letter is a request for you to take part in a research project to assess principal leadership styles in West Virginia elementary schools. This project is being conducted by Gus Penix, a doctoral student in the Educational Leadership Studies Department of WVU. Your participation in this project is greatly appreciated and should take no more than five to ten minutes to complete the online questionnaire.

Your involvement in this project will be kept as confidential as legally possible. Surveys are nameless and data received for each school surveyed will be confidentially maintained and not released. All data will be reported in the aggregate. I will not ask any information that will lead back to your identity as a participant. Your participation is completely voluntary. You may skip any question that you do not wish to answer and you may discontinue at any time. WVU's Institutional Review Board acknowledgement of this project is on file.

I hope that you will participate in this research project, as it could be beneficial in providing data for potential use by the West Virginia Department of Education in planning and developing future leadership initiatives, and by higher education institutions in planning and developing leadership studies course work. Thank you very much for your time. Should you have any questions about this letter or the research project, please contact me at the following e-mail address, gpenix @access.k12.wv.us.

How to complete the survey:

Access the online Teacher's questionnaire at the following web address: http://www.zoomerang.com/Survey/?p=WEB228CNE.

Thank you for your time and help with this project.

Sincerely,

GusPenix 


\section{APPENDIX G}

$\underline{\text { Follow-up Telephone Conversation Script - Requesting Survey Participation }}$

School

Principal's Survey Received? Yes No
Date $1^{\text {st }}$ call_ $2^{\text {nd }}$ call_ $3^{\text {rd }}$ call

Principal

Recently you received a packet in the mail requesting your school's participation in a research project undertaken by me (Gus Penix) regarding principals' leadership styles in West Virginia elementary schools. As of today , I have (a) not received any responses from either the principal or teachers, (b) received the principal's survey but no teachers' surveys, (c) received the principal's survey and teachers' surveys, or (d) received teacher surveys and no principal's survey.

Results from this study will provide valuable data for potential administrative training initiatives and course work for aspiring administrators.

Your school's participation would be greatly appreciated.

If any materials are needed for completing the process, I would be happy to FAX or email them to you.

FAX No. e-mail address 


\section{APPENDIX H}

\section{West WrininiaUniversity \\ Office of Research Compliance}

Expedited - IRB Protocol - Exemption

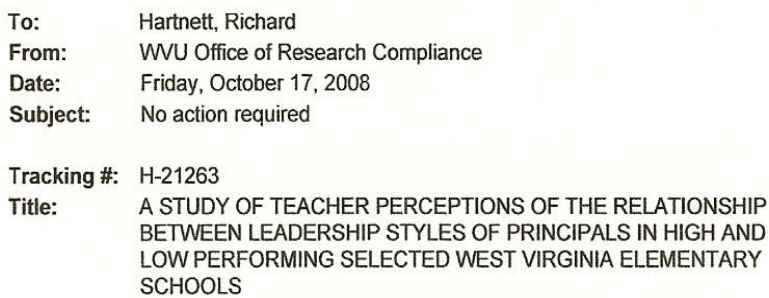

The above-referenced study was reviewed by the Institutional Review Board and was granted exemption on [Review Date Not Found] in accordance with 45 CFR 46.101(2)

While no action is required on your part, the IRB made the following findings:

This research study was granted an exemption in accordance withEducational tests, survey procedures, interview procedures, or observation of public behavior [45 CFR 46.101(2)].

The following documents have been approved and validated for use in this study and are available in the BRAAN system:

Surveys, Questionnaires, Interviews

Attachments

Principal Survey.pdf Principal Survey

Teacher Survey.pdf Teacher Survey

Miscellaneous Attachments

Attachments

Principal Letter.doc Principal Participant Letter

Teacher Letter.doc Teacher Participant Letter

Thank you.
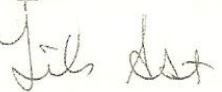

Board Designee: Ast, Lilo

Letter Sent By: Ast, Lilo, 10/17/2008 11:20 AM

Once you begin your human subject research the following regulations apply:

1. Unanticipated or serious adverse events/side effects encountered in this research study must be reported to the IRB within five (5) days.

2. Any modifications the study protocol or informed consent form must be reviewed and approved by the IRB prior to implementation.

3. You may not use a modified informed consent form until it has been approved and validated by the IRB. 


\begin{abstract}
APPENDIX I
$\underline{\text { Permission to Use Bolman and Deal's Four Frame Model Overview }}$

Dear Mr. Penix:

Terry Deal and I are pleased to give you permission to use Table 1.1 in your doctoral dissertation.

Best wishes.

Lee G. Bolman, Interim Dean

Professor and Marion Bloch/Missouri Chair in Leadership

Bloch School of Business and Public Administration

University of Missouri-Kansas City

5100 Rockhill Road

Kansas City, MO 64110

Tel: (816) 235-5407

Fax: (816) 235-6529

Email: bolmanl@umkc.edu

Web site: www.leebolman.com
\end{abstract}

From: gpenix@access.k12.wv.us [mailto:gpenix@access.k12.wv.us]

Sent: Sunday, January 18, 2009 6:34 PM

To: Bolman, Lee G.

Cc: gpenix@access.k12.wv.us

Subject: Table Permission

Dr. Lee G. Bolman

Professor and Marion Bloch/Missouri Chair in Leadership

Bloch School of Business and Public Administration

University of Missouri-Kansas City

5100 Rockhill Road

Kansas City, MO 64110

Dear Dr. Bolman:

I am requesting your permission to reprint Table 1.1, Overview of the Four Frame Model, from Reframing Organizations: Artistry, Choice, and Leadership (2003) in my doctoral dissertation. The table will be used in the Literature Review chapter to concisely describe and define the four frames.

Your consideration in this matter is greatly appreciated.

Sincerely,

Gus Penix 


\begin{abstract}
APPENDIX J
Permission to Use Bolman and Deal's Reliability of Leadership Orientation Scales

I'm happy to offer permission to use the table that you constructed from our data.

Best wishes.

Lee G. Bolman, Interim Dean

Professor and Marion Bloch/Missouri Chair in Leadership

Bloch School of Business and Public Administration

University of Missouri-Kansas City

5100 Rockhill Road

Kansas City, MO 64110

Tel: (816) 235-5407

Fax: (816) 235-6529

Email: bolmanl@umkc.edu

Web site: www.leebolman.com
\end{abstract}

From: gpenix@access.k12.wv.us [mailto:gpenix@access.k12.wv.us]

Sent: Thursday, February 19, 2009 6:15 PM

To: bolmanl@umkc.edu

Cc: gpenix@access.k12.wv.us

Subject: Reliability Scales

Dear Dr. Bolman,

I have constructed a table from data found in the Research section of your website.

The table is entitled Reliability of Leadership Orientation Scales and it details the Coefficient Alpha (all items) and the Number of Cases Completed for each of the four frames.

I am requesting your permission to utilize this data in my doctoral dissertation.

Your consideration is greatly appreciated.

Gus Penix

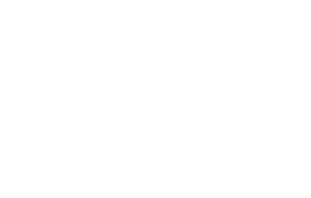

